\title{
Financial Markets and the Macro Economy
}

\author{
Menachem Brenner, Paolo Pasquariello, \\ and Marti Subrahmanyam ${ }^{1}$
}

May 17, 2006

\footnotetext{
${ }^{1}$ Stern School of Business, New York University, Ross School of Business at University of Michigan, and Stern School of Business, New York University, respectively. Please address comments to the corresponding author (Brenner) at the Stern School of Business, New York University, Finance Department, 44 West $4^{\text {th }}$ Street, Suite 9-55, New York, NY 10012, or via email at mbrenner@stern.nyu.edu. We have benefited from the comments of Robert Engle, Clara Vega, Guojun Wu, and participants in seminars at Monash University and Bank of Korea. Any remaining errors are our own.
} 


\begin{abstract}
The objective of this paper is to provide a deeper insight into the links between financial markets and the real economy. To that end, we study the short-term anticipation and response of U.S. stock, Treasury, and corporate bond markets to the first release of U.S. macroeconomic information. Specifically, we focus on the impact of these announcements not only on the level, but also on the volatility and comovement of those assets' returns. For that purpose, we estimate several extensions of the parsimonious amended GARCH model of Engle (2002) for the excess holding-period returns on seven portfolios of these asset classes. We find that the process of price formation in the U.S. financial markets appears to be driven by fundamentals; yet, "excessive" volatility and comovement play an important role in return dynamics as well. Further, our analysis reveals a statistically and economically significant dichotomy between the reaction of the stock and bond markets to the arrival of unexpected fundamental information. However, we also show that stock and bond returns tend to react to the expected component of these announcements. Overall, the above results often differ from earlier studies where the surprise portion of those releases was not identified, and shed new light on the mechanisms by which information is incorporated into prices.
\end{abstract}

JEL classification: C32; G14

Keywords: Volatility; Comovement; Information; Market Efficiency 


\section{Introduction}

"Job report sends stocks and bonds sharply lower ...

The yield on the Treasury's 10-year note ... shot up to 4.78\%, its highest in 22 months ... after the Labor Department said on yesterday morning that 288,000 new jobs were created in April, about 100,000 more than had been expected ...

Stocks fell initially, rebounded but then collapsed in the afternoon, ending at their lows for the day ..."

Source: New York Times.

Despite the skepticism about newspaper accounts of financial market behavior among academics, there seems to be little doubt that the release of macroeconomic news has a significant impact on prices of securities within as diverse asset classes as stocks, Treasury bonds, and corporate bonds. For instance, most asset pricing models provide a snapshot of the cross-sectional relationship between asset returns (or prices) and risk factors at a given point in time. A change in one or more of these factors should therefore affect asset returns, with the dynamic nature of these changes being dictated by the dynamics of new information arriving to the market. Consistently, basic economic theory (see Andersen et al., 2004 for a review) suggests that asset price changes should depend on news affecting cash flows, discount rates, and risk premia.

The dominant paradigm regarding the response of asset prices to new information (first articulated by Fama, 1971) is that, since markets are efficient, asset prices should react immediately, and in an unbiased manner, to new information. In the first two decades of modern empirical finance, since the mid 1960s, the analysis of the response of market prices to micro, firmlevel, information led to the broad conclusion that the markets are indeed efficient, albeit to various degrees (weak, semi-strong, or strong). Therefore, asset prices should generally react only to the unexpected portion of news, and not to the part that has already been anticipated by the market. Yet, assessing the net effect of news arrivals on asset prices is difficult, as the former may have an impact on more than one of the fundamental factors driving the latter. For example, the announcement of an increase in the unemployment rate may be bad news for the economy (lower profitability) but good news for short term interest rates, leaving the net effect ambiguous. In addition, the notion of market efficiency has been challenged in the past decade by the 
discovery of several anomalies, many of which are based on the psychology of investors. ${ }^{1}$ Some recent studies even suggest that there may be a (possibly rational) disconnect between the first and higher order moments of asset returns and their fundamentals. ${ }^{2}$

In this paper, we intend to explore the functioning of the process of price formation in all three of the main U.S. financial markets - stocks, government bonds, and corporate bonds - around the dates of important macroeconomic news events. In particular, we concentrate on employment, inflation, and interest rate news. There is broad agreement that the level and dynamics of employment and inflation within a country adequately capture the strength of its economy. Employment and inflation, in turn, may drive and/or be driven by the short-term interest rates set by the U.S. monetary authorities. Efficient financial markets would then react to news about them, insofar as they provide information about the payoffs of the traded assets and the rates at which to discount them. Therefore, the release of employment, inflation, and interest rate news should ultimately affect the behavior of returns on both government and corporate securities. We proxy for these releases by focusing on four real-time U.S. macroeconomic announcements: Consumer Price Index, Nonfarm Payroll Employment, and Civilian Unemployment news, exogenously released on a monthly basis, and Fed Funds Target Rate decisions, instead potentially endogenous to the former. ${ }^{3}$

Based on the above considerations, we intend to address four basic sets of questions in this study. First, what is the impact of these crucial macroeconomic news on asset returns and asset return volatility in the proximity of their first release? Are the markets where these assets are traded more volatile before the news event and less volatile afterward? This would be the case, for example, if the arrival of information leads to resolution of uncertainty among market participants. Or, is that arrival instead destabilizing, e.g., when inducing greater uncertainty about the future economic environment?

Second, do the news releases affect the markets for different asset classes in different ways? The rationale for heterogeneity in the fluctuations of stock

\footnotetext{
${ }^{1}$ See the survey of Hirshleifer (2001) and references therein

${ }^{2}$ E.g., Kodres and Pritsker (2002), Kallberg and Pasquariello (2004), Pasquariello (2005), Yuan (2005), and references therein.

${ }^{3}$ Among the various measures of inflation, the CPI is considered its best proxy and is the number usually followed by the Federal Reserve. Statistics about the unemployment rate and nonfarm payroll are included in the same news release on the same day. We use both statistics in our study, since they are less than perfectly negatively correlated and the former is highly predictable while the latter is not. Many earlier studies (e.g., Jones et al., 1998) focus exclusively on the employment news data.
} 
and (government and corporate) bond returns in response to macroeconomic news is intuitive. For instance, higher inflation may increase only the volatility of the bond market, since stocks (and, to a lesser extent, corporate bonds) offer a natural hedge against inflation.

Third, do these macroeconomic announcements affect the existing degree of correlation between different asset classes? Indeed, correlation shifts could stem from more intense portfolio rebalancing activity across stocks and bonds (e.g., Fleming et al., 1998; Kodres and Pritsker, 2002) or from greater dispersion of beliefs among speculators (as in Pasquariello, 2005) before and after their arrivals.

Fourth, is the impact of these news releases driven exclusively by their unexpected component or are they reacting even to anticipated information? Is the adjustment instantaneous or protracted over time? Is the increase in volatility and comovement persistent?

To tackle these questions, we combine a database of daily excess holdingperiod returns on seven portfolios of stocks traded on the NYSE-AMEX and NASDAQ, of five, ten, and thirty-year Treasury bonds, and of Aaa and Baa-rated long-term corporate bonds with data on those four macroeconomic announcements and their consensus expectations between 1986 and 2002. The choice of daily spot data is not casual. It in fact enables us to determine whether the effects described above are both economically and statistically meaningful over asset classes and horizons of relevance to analysts, investors, and policymakers. Some of those effects may not persist long enough to be measured at lower frequencies. Further, higher frequency spot and futures data are either unavailable or nonexistent over some subsets of our sample period and/or for some of the asset classes in this study. Lastly, higher frequency data, whether for spot or futures prices, are plagued by microstructure frictions (e.g., bid-ask bounce, quote clustering, price staleness, inventory considerations) that may bias any inference drawn upon them while becoming generally immaterial over longer intervals. ${ }^{4}$ The expectation data, from the International Money Markets Services survey (for macroeconomic variables) and from futures prices (for Fed Funds rate decisions), are customarily assumed to represent unbiased estimates of the anticipated portion of these announcements. ${ }^{5}$ Hence, they allow us to identify the true news component in those information arrivals, i.e., to remove the component of this information which, in efficient markets, should have already been incorporated into asset prices before being released to the public. We then estimate

\footnotetext{
${ }^{4}$ E.g., see the discussion in Hasbrouck (2004).

${ }^{5}$ The main properties of these datasets, as well as references to their use in the literature, are provided in Section 4.
} 
the impact of these events on conditional returns, return volatility, and return covariance using several extensions of the GARCH(1,1)-DCC IMA model of Engle (2002). This specification, albeit more flexible and parsimonious than most available multivariate models, has been shown to perform equally well in a variety of situations.

The objective of our study is to contribute to the empirical literature relating macroeconomic fundamentals to asset pricing dynamics. The development of asset pricing models including macroeconomic risk factors dates back to the Intertemporal Capital Asset Pricing Model (ICAPM) of Merton (1973), but it was the empirical analysis of Chen et al. (1986) that inspired further investigations of the effect of macroeconomic variables on asset returns. Chen et al. (1986) argued that surprise shocks to macroeconomic factors (such as inflation and industrial production) should affect the discount rate and the expected cash flows of individual firms and, in turn, their stock returns. Yet, their econometric approach yielded only mixed results. Consequently, many of the ensuing studies concentrated explicitly on the impact of various macroeconomic news announcements on asset prices.

These studies differ on multiple grounds: Their choice of news, their choice of market (bonds, stocks, or currencies), the moments of the return distribution they examine, and the statistical methodology they employ. To cite few examples among the most recent of them (to conserve space), Balduzzi et al. (2001) and Andersen et al. (2004) include all available macro announcements, while Jones et al. (1998), Fleming and Remolona (1999), Bomfim and Reinhart (2000), Kuttner (2001), Bomfim (2003), and Bernanke and Kuttner (2005) limit their analyses to distinct subsets of them, either by choice or because of data availability. Jones et al. (1998), Fleming and Remolona (1999), Balduzzi et al. (2001), and Pasquariello and Vega (2005) analyze the impact of macroeconomic news on the U.S. Treasury spot market; Li and Engle (1998) and Kuttner (2001) examine the reaction of U.S. Treasury and Fed Funds futures to their release; Connolly and Wang (2000), Bomfim (2003), Boyd et al. (2004), and Bernanke and Kuttner (2005) concentrate on the stock markets, either U.S. or foreign. Fewer studies focus on the simultaneous impact of macroeconomic news releases on both stocks and government bonds (e.g., Bomfim and Reinhart, 2000) or their futures (Andersen et al., 2004), and none on the corporate bond market. Some of these studies do not separate the expected component of the released information from the unexpected one (e.g., Jones et al., 1998; Fleming and Remolona, 1999). Those that do estimate the expected component either with futures contracts, whenever available and relevant (e.g., Kuttner, 2001), with analysts' surveys (e.g., Bomfim, 2003), or with statistical models (e.g., Boyd et al., 2004). Most of these studies limit their empirical investigations to the 
first and second moments of asset returns. Fleming et al. (1998) consider the volatility linkages of stocks, bonds, and money market instruments, but do not specifically relate the estimated volatility spillovers to macro news announcements. Connolly and Wang (2000) and Andersen et al. (2004) examine the impact of these news only on cross-country linkages, not crossdomestic market linkages, and only among mean asset returns.

Our research differs from the aforementioned literature (as well as from other existing related studies not mentioned above) on several important dimensions. First, we investigate the impact of the most relevant macroeconomic news (inflation, employment, and interest rates) on the joint distribution of the returns in the three most important U.S. financial markets: Equity, Treasury bonds, and corporate bonds. This is arguably a reasonable course of action, since each of these markets does not exist in a vacuum and investors can, and often do, hold and trade many of those securities at the same time. Furthermore, our focus on a subset of all U.S. macroeconomic news releases improves the clarity of the analysis, since most other such announcements play only a limited role in the dynamics of either stock or government bond prices (e.g., Andersen at al., 2004; Pasquariello and Vega, 2005). Second, we use survey and futures data to extract the unexpected components of these news announcements. Third, we analyze the impact of their release on both the returns from the three sets of assets, as well as their volatility and correlations. This effort allows us to provide a more comprehensive picture of the effect of macroeconomic information on the behavior of asset prices in the U.S. capital markets, and to assess their relative efficiency.

We find that the process of price formation in the U.S. financial markets appears to be driven by fundamentals; yet, "excessive" volatility and comovement also play an important role in return dynamics. Specifically, our evidence reveals a statistically and economically significant dichotomy between the reaction of the stock and bond markets to the release of unanticipated fundamental information. After initially falling, conditional stock return volatility increases the day these surprise macroeconomic news are released. Conditional bond return volatility instead first rises and then declines, the more so the shorter the maturity of the bond portfolio and the greater its likelihood of default. However, we show that stock and bond returns tend to react to the expected component of these announcements as well. Finally, we find that conditional excess return comovement within and across stock and bond markets generally decreases in correspondence with those releases, even after controlling for volatility shifts. Overall, these results often differ from earlier studies where the surprise portion of news releases could not be identified (e.g., Jones et al., 1998) and shed new light on the mechanisms by which information is incorporated into prices. 
The remainder of the paper is organized as follows. Section 2 uses the relevant economic and financial literature to identify a set of working hypotheses on the impact of news releases on stock and bond returns. Section 3 develops our econometric approach to estimating such impact. Section 4 describes our database. Section 5 summarizes the first set of results for conditional returns, return volatility, and return comovement. Section 6 tests for the differential effect of positive and negative news on stock and bond return dynamics, while Section 7 explores the question of the efficiency of the markets for stocks, government and corporate bonds. Section 8 concludes.

\section{News and price discovery}

In this paper, we study the short-term anticipation and response of the U.S. stock, Treasury, and corporate bond markets to the arrival of relevant U.S. macroeconomic news. The goal of our multi-market analysis is to shed light not only on the effects of these news on mean excess returns and conditional return volatility, but also on the comovement and interaction between those markets in the proximity of their occurrence.

The analysis of Ross (1989) motivates the study of the relation between information flow and volatility. Ross argued that, in an arbitrage-free economy, the volatility of prices should be related to the arrival of information to an efficient market. Foster and Viswanathan (1993) and Pasquariello and Vega (2005) also showed that, ceteris paribus, both the availability and the realizations of a public signal increase price volatility. This close relation can nonetheless manifest itself in different ways depending on the degree of uncertainty surrounding the announcement and the degree of disagreement among investors regarding its content.

Intuitively, employment, inflation, and interest rate news may have a direct or indirect impact on the beliefs of market participants about the final payoffs of stocks and (government and corporate) bonds. Fed Funds short-term rate decisions and employment and inflation shocks could in fact affect the discount rate for future cash flows as well as their magnitude and likelihood. ${ }^{6}$ Yet, regardless of the prevailing directional effect on beliefs and prices, the release of this information may influence investors' uncertainty about future realizations of the macroeconomic variables, hence about assets' future payoffs. As often argued (e.g., Veronesi, 1999 and references therein), current return volatility is the best proxy for such uncertainty. The arrival

\footnotetext{
${ }^{6}$ The effects of different macroeconomic news on the levels of asset returns is discussed in greater detail below, in correspondence with conjecture $C(6)$.
} 
of any economically relevant announcement may then either increase this volatility or reduce it.

Consistently, the existing literature on equity and Treasury bond markets (e.g., Jones et al., 1998; Li and Engle, 1998; Bomfim, 2003) suggests two distinct possibilities. The "calm before the storm" hypothesis states that, on the days prior to important news announcements, financial markets are usually tranquil, their prices having already reflected those news' expected content and uncertainty. However, the subsequent release of unexpected macroeconomic information may have a destabilizing effect on asset returns and return volatility. For example, this would be the case if news arrival leads to greater uncertainty and disagreement among market participants about its implications for current asset valuations, potential policy moves, or the state of the economy. We translate this argument in the following conjecture:

$C(1)$ : Conditional return volatility is lower in the days immediately preceding, and higher on the day of the arrival of both positive and negative macroeconomic surprises.

Alternatively, macroeconomic announcements may resolve previously high uncertainty or attenuate pervasive differences in private information among traders about assets' payoffs. For instance, Pasquariello (2005) showed that, ceteris paribus, more information heterogeneity among insiders increases equilibrium price volatility and comovement. Hence, surprise macroeconomic news may lessen the degree of confusion or dispersion of beliefs among market participants, thus reducing conditional return volatility. We summarize this "storm before the calm" argument in the following conjecture:

$C(2)$ : Conditional return volatility is higher in the days immediately preceding, and lower on the day of the arrival of both positive and negative macroeconomic surprises.

The pattern of conditional return volatility following the release of news about inflation and employment is also of interest to this study. Specifically, we are interested in whether the volatility shocks described above are of a transitory or persistent nature. Jones et al. (1998) observe that clustering of information arrivals, market sentiment, or gradual learning considerations may all justify why an increase in conditional volatility would persist over time. Further, the timing of these macroeconomic releases is not clustered and is exogenous to financial markets. ${ }^{7}$ Therefore, lack of persistence in

\footnotetext{
${ }^{7}$ Moreover, it is reasonable to assume that no other news released immediately following target rate, CPI, payroll, and unemployment information is important enough to systematically induce additionally intensifying or offsetting volatility shocks.
} 
announcement shocks would suggest that additional information gathering or the trading process do not intrinsically increase return volatility. Some supporting evidence is provided by Jones et al. (1998) for the U.S. Treasury market using actual (rather than unexpected) labor and producer price announcements.

$C(3)$ : Conditional return volatility is lower in the days immediately following the arrival of both positive and negative exogenous macroeconomic surprises.

Although the schedule for the release of CPI, payroll, and unemployment is exogenous to the U.S. financial markets, both the timing and the content of the target rate decisions by the Federal Reserve are possibly endogenous. Indeed, the sequence of publicly observable events (including the above macroeconomic announcements) and the nature of policy-making by a monetary authority may make the resulting news-generating process for target rate decisions autocorrelated, hence autocorrelated volatility consistent with market efficiency. ${ }^{8}$ This effect may in turn enhance, attenuate, or even dominate those reported in $C(1)$ to $C(3)$, thus leading to the following conjecture:

$C(4)$ : The behavior of conditional return volatility around the dates of surprise Fed decisions differs from what is postulated in $C(1)$ to $C(3)$.

As the quote in Section 1 suggests, the financial press frequently emphasizes the greater degree of comovement among financial markets in the proximity of the release of macroeconomic news. There are several reasons why this may occur. First, asset prices move together when those news announcements simultaneously affect expectations in more than one market. This is what Fleming et al. (1998) call the "common information" argument. Second, the release of unexpected macroeconomic information may trigger rebalancing activity across asset classes due to portfolio considerations. ${ }^{9}$ Similarly, investors may react to an uncertain macroeconomic environment by "flying to quality" (i.e., to government notes and bonds) and away from riskier corporate securities. Alternatively, comovement among asset prices

\footnotetext{
${ }^{8}$ Nonetheless, Jones et al. (1998) do not find any evidence that the Federal Reserve is more likely to change the target rate on days immediately following Producer Price Index (PPI), nonfarm payroll, and unemployment announcements.

${ }^{9}$ For instance, the announcement of an unexpected increase in CPI, in an economy just emerging from a recession, may induce investors to shift their holdings from bonds to stocks, since the latter are generally deemed to provide a better hedge against future inflation.
} 
is deemed excessive when unjustified by the underlying fundamental links among their payoffs.

The nature of linkages and information spillovers across markets has been extensively scrutinized; in particular, a growing body of empirical evidence suggests that excess return volatility and comovement are pervasive to most capital markets during both tranquil and uncertain times. ${ }^{10}$ Many of the explanations proposed for this phenomenon concentrate on the trading process, i.e., on the trading activity of market participants, in the presence of information asymmetry and heterogeneity, as well as of market imperfections and frictions. ${ }^{11}$ The arrival of surprise news is likely to accentuate the relevance of most of these arguments. For example, the release of macroeconomic information may reduce the extent of information asymmetry and/or heterogeneity among market participants (hence decreasing excess comovement), induce investors to revise their speculative positions, or make some financial constraints more binding for them (instead increasing excess comovement). Measurement issues are the object of considerable debate as well, since Forbes and Rigobon (2002) argued that shifts to conditional correlation may be unrelated to a spillover effect in the presence of greater conditional volatility. Therefore, we argue here that evidence of shocks to conditional covariance induced by surprise macroeconomic news, after controlling for their impact on mean returns and conditional volatility, provides support to the notion of excess comovement among U.S. financial markets. We formalize this conjecture as follows:

$C(5)$ : Surprise macroeconomic news announcements may have an excessive impact on conditional return covariances in the proximity of their release.

We also focus our attention on the levels of asset returns. Much empirical and theoretical literature has explored the reaction of stock and bond prices to macroeconomic announcements. ${ }^{12}$ As mentioned earlier, it is argued there that the impact of news arrivals on asset prices occurs through any of the following three factors: Expected cash flows from the assets, the appropriate discount rates, and their risk premia. The impact on government bond prices is the least controversial; for example, the general equilibrium model

\footnotetext{
${ }^{10}$ A list of recent contributions includes Shiller (1989), King and Wadhwani (1990), Pindyck and Rotemberg (1990, 1993), Karolyi and Stulz (1996), Connolly and Wang (2000), Barberis et al. (2002), Forbes and Rigobon (2002), and Kallberg and Pasquariello (2004).

${ }^{11}$ Kyle and Xiong (2001) and Kallberg and Pasquariello (2004) review the state of the theoretical literature on excess comovement.

${ }^{12}$ See Andersen et al. (2004) for a survey of the most recent contributions.
} 
à la Lucas (1982) in Andersen et al. (2004) shows that surprise inflation or real activity shocks should increase risk-free bond yields. The available empirical evidence supports this argument (e.g., Balduzzi et al., 2001). Ensuing increased macroeconomic risk may also play a role. French et al. (1987) suggest that greater price volatility is usually accompanied by higher expected returns. Consistently, Jones et al. (1998) find that, when accompanied by greater conditional volatility, actual PPI and employment announcements also induce higher expected returns.

Chen et al. (1986) were the first to explicitly identify an empirical link between several macroeconomic variables and expected stock returns in the context of a multi-factor cross-sectional asset pricing model. Assessing the impact of news arrivals on stocks and corporate bonds is more ambiguous, since their prices do not depend solely on future interest rates. A positive macroeconomic shock (e.g., unemployment decline) may increase a corporation's expected rate of growth of dividends and decrease the likelihood of default on its debt, thus increasing its stock and corporate bond prices, ceteris paribus for their risk premia. Yet, the same shock may also increase the rates at which the future cash flows from these assets are discounted. Recent research (e.g., Andersen et al., 2004; Boyd et al., 2004) further shows that the resulting net impact on stock prices may be state-dependent, i.e., that the dominance of the former effect over the latter (or vice versa) is driven by the aggregate health of the economy. One of the objectives of this paper is to identify the relative strength of these effects for the broadest range of asset classes in the U.S. financial market, including the corporate bond market. We therefore assess the relevance of the following conjecture:

$C(6)$ : The contemporaneous impact of positive (negative) macroeconomic surprises is positive (negative) on bond returns, and ambiguous on stock and corporate bond returns.

Finally, we intend to analyze the impact of expected announcements on the U.S. financial markets. All of the above arguments assume in fact that the news arrivals have some information content for market participants. If they have not, market efficiency implies that the reaction of conditional returns, volatility, and covariances to their releases should be insignificant. Yet, any evidence of the contrary would be supportive of the role played by the trading process, or by market sentiment in generating excess volatility and comovement among asset returns. This is captured by the following conjecture:

$C(7)$ : Anticipated macroeconomic announcements should have no impact 
on stock, government, and corporate bond returns, return volatility, and their interaction.

\section{The empirical model}

The main objective of this study is to analyze the short-term behavior of the U.S. financial market in proximity of the release of macroeconomic news. In this section, we describe the empirical methodology we use for that purpose. The GARCH specification proposed by Bollerslev (1986) and its many univariate and multivariate extensions are among the most widely adopted models to describe time-varying volatility and covariances. ${ }^{13}$ Their success can be attributed to the ability to provide robust descriptions of many volatility processes (see Nelson, 1990; Nelson and Foster, 1994). Moreover, a large body of literature now exists on the theoretical properties of their estimators. ${ }^{14}$ Yet, in most cases, multivariate GARCH models are not flexible enough, and the number of parameters in them too big, to introduce complex forms of conditional comovement among asset returns. In this paper, we use the Dynamic Conditional Correlation (DCC) model introduced by Engle (2002). Indeed, the DCC specification has the flexibility of univariate GARCH models without the complexity of traditional multivariate GARCH specifications. We start by proposing the following $\operatorname{GARCH}(1,1)$ model to describe the evolution of daily excess asset returns $r^{i}$ :

$$
\begin{aligned}
r_{t}^{i} & =\mu_{i}^{e}+\rho_{i}^{e} r_{t-1}^{i}+\gamma_{i}^{e}(0) I_{t}^{e}(0)+\varepsilon_{t}^{i} \\
\varepsilon_{t}^{i} & =\sqrt{s_{t}^{i}} e_{t}^{i} \quad e_{t}^{i} \mid \digamma_{t-1} \sim N\left(0, h_{t}^{i}\right) \\
h_{t}^{i} & =\omega_{i}^{e}+\alpha_{i}^{e}\left(e_{t-1}^{i}\right)^{2}+\beta_{i}^{e} h_{t-1}^{i},
\end{aligned}
$$

where $\digamma_{t-1}$ denotes the information set and $s_{t}^{i}=1+\sum_{k=-1}^{+1} \delta_{i}^{e}(k) I_{t}^{e}(k)$.

According to Engle (1995, p. xii), the $\operatorname{GARCH}(1,1)$ is "the leading generic model for almost all asset classes of returns." The above specification - a simple extension of those in Andersen and Bollerslev (1997, 1998), Jones et al. (1998), and Bomfim (2003), among others - allows for news arrivals to affect both the long-term $\left(\frac{\omega_{i}^{e}}{1-\beta_{i}^{e}}\right)$ and transitory $\left(\alpha_{i}^{e} \sum_{n=0}^{\infty}\left(\beta_{i}^{e}\right)^{n}\left(e_{t-n-1}^{i}\right)^{2}\right)$ components of the $\operatorname{GARCH}(1,1)$ variance $h_{t}^{i}$. Specifically, in Eq. (1), $I_{t}^{e}(k)$

\footnotetext{
${ }^{13}$ An incomplete list of univariate models includes the IGARCH model of Engle and Bollerslev (1986), the ARCH-M regression of Engle et al. (1987), and the EGARCH model of Nelson (1991); popular multivariate extensions are the VECH model of Bollerslev et al. (1988), the CCORR model of Bollerslev (1990), and the BEKK model of Engle and Kroner (1995). For more on the properties of these specifications, see Kroner and Ng (1998).

${ }^{14}$ See Lumsdaine (1996) for a review.
} 
is an event dummy equal to one if a surprise macroeconomic event of type $e$ occurred at time $t+k$ and equal to zero otherwise. We can interpret the corresponding dummy coefficients in the expression for $h_{t}^{i}$ in Eq. (1) as proxies for the (sequential) impact of news arrivals on conditional excess return variance. Hence, $\delta_{i}^{e}(1)$ is a measure of anticipation, i.e., of the marginal percentage impact of the release of macroeconomic information on the conditional variance of the excess return $r^{i}$ before that release actually occurs at time $t+1$. The coefficient $\delta_{i}^{e}(0)$ is a proxy for the additional, contemporaneous marginal percentage impact of the news release on $h_{t}^{i}$. Finally, the coefficient $\delta_{i}^{e}(-1)$ is a measure of persistence, i.e., of the additional marginal percentage impact of the news arrival on $h_{t}^{i}$ after the information has already been revealed at time $t-1$. In other words, we can interpret the model of Eq. (1) as a conditional version of a simple unconditional event study of the behavior of the second moment of asset returns around the official dates of the release of macroeconomic announcements. As standard in the finance literature, Eq. (1) also specifies a first-order autocorrelation model for excess holding-period returns, to control for nonsynchronicity in prices, microstructure effects, and gradual convergence to equilibrium. We further account for the possibility that surprise macroeconomic news affect the first moment of asset returns (e.g., Boyd et al., 2004), in addition to the conditional variance $h_{t}^{i}$, by including the dummy $I_{t}^{e}(0)$ in the process for $r^{i}$, as in Jones et al. (1998); hence, consistent with the variance specification, the coefficient $\gamma_{i}^{e}(0)$ measures the impact of the macroeconomic event $e$ on the mean excess return on the announcement dates and is comparable across events.

We also intend to study the impact of news arrivals on the structure of conditional correlation among asset classes. There is a growing body of literature investigating the extent of information spillover from a market to another (e.g., Fleming et al., 1998; Kallberg et al., 2005 and references therein) and the extent to which it may be deemed excessive (e.g., King and Wadhwani, 1990; Pindyck and Rotemberg, 1990, 1993; Kallberg and Pasquariello, 2004). Yet, Forbes and Rigobon (2002) showed that the increase in conditional correlation among asset returns in proximity of certain macroeconomic events may be due to an increase in return volatility, i.e., to heteroskedasticity. We tackle this problem by assuming that the conditional covariance between any two standardized residuals $\eta_{t}^{i}=\frac{\varepsilon_{t}^{i}}{\sqrt{s_{t}^{i} h_{t}^{i}}}$ and $\eta_{t}^{j}=\frac{\varepsilon_{t}^{j}}{\sqrt{s_{t}^{j} h_{t}^{j}}}$ at time $t$, given all the information available at time $t-1, q_{t}^{i j}$, is described accurately by the following exponential smoother:

$$
q_{t}^{i j}=s_{t}^{i *}\left[\lambda^{e} q_{t-1}^{i j}+\left(1-\lambda^{e}\right) \eta_{t-1}^{i} \eta_{t-1}^{j}\right]
$$

where $s_{t}^{i *}=1+\sum_{k=-1}^{+1} d_{i}^{e}(k) I_{t}^{e}(k)$. We add $\eta_{t}^{i} \eta_{t}^{j}$ to both sides of Eq. (2) to 
obtain an integrated moving average (IMA) process with no intercept,

$$
\eta_{t}^{i} \eta_{t}^{j}=s_{t}^{i *} \eta_{t-1}^{i} \eta_{t-1}^{j}+\left(q_{t}^{i j}-\eta_{t}^{i} \eta_{t}^{j}\right)-\lambda^{e} s_{t}^{i *}\left(q_{t-1}^{i j}-\eta_{t-1}^{i} \eta_{t-1}^{j}\right)
$$

where the errors $q_{t}^{i j}-\eta_{t}^{i} \eta_{t}^{j}$, with a conditional mean of zero, are Martingale differences by construction and can be thought of as white-noise sequences. Eq. (3) is an extension of the DCC IMA model of Engle (2002) with common cross-asset adjustments $\left(\lambda^{e}\right)$. More importantly, we use the above model in this paper to measure the anticipated $\left(d_{i}^{e}(1)\right)$, contemporaneous $\left(d_{i}^{e}(0)\right)$, and persistent $\left(d_{i}^{e}(-1)\right)$ effect of the arrival of news on conditional correlations in a parsimonious way, while controlling for the impact of these arrivals on conditional volatility and mean excess returns, as advocated by Forbes and Rigobon (2002). Indeed, any common fundamental information shock stemming from the news arrival at time $t$ affects directly the processes for $r_{t}^{i}$ and $h_{t}^{i}$ in Eq. (1), via the parameters $\gamma_{i}^{e}(0), \delta_{i}^{e}(-1), \delta_{i}^{e}(0)$, and $\delta_{i}^{e}(1)$. Therefore, we deem the impact of these arrivals on the comovement between any pair of standardized residuals $\eta_{t}^{i}$ and $\eta_{t}^{j}$ (the ensuing unpredictable portions of the fluctuations in asset prices), measured by the parameters $d_{i}^{e}(1), d_{i}^{e}(0)$, and $d_{i}^{e}(-1)$, as "excessive." 15

The model of Eqs. (1) and (3) provides a basic representation of the behavior of asset returns in proximity of macroeconomic news announcements. As such, it is designed to capture only the first-order, symmetric impact of news arrivals on the U.S. equity and bond markets. Therefore, evidence from its estimation in support of any of the conjectures in Section 2 can be interpreted as strong evidence. We investigate second-order effects, in particular the possibly asymmetric impact of "good" and "bad" news on return dynamics, in Section 6. As first suggested by Engle (2002), the model of Eqs. (1) and (3) is estimated in two steps. In the first step, Eq. (1) is estimated separately for each asset $i$ by the quasi-maximum likelihood (QML) procedure described in Bollerslev and Wooldridge (1992). Hence, the resulting estimates are consistent and asymptotically efficient. In the second step, the parametric model of Eq. (3) is estimated again by quasi-maximum likelihood, using the parameters obtained in the first step. Under some mild

\footnotetext{
${ }^{15}$ In a recent paper, Andersen, Bollerslev, Diebold, and Labys (2003) argue that modelfree estimates of daily variances from intraday return data perform well in comparison with standard GARCH models of daily volatility. Along those lines, Christiansen and Ranaldo (2005) use futures intraday data to measure realized Treasury bond-U.S. stock return correlations in proximity of macroeconomic news announcements. However, inference drawn upon these approaches may be biased for they do not control for the contemporaneous impact of those news arrivals on conditional return levels when estimating realized volatility, as well as on conditional return volatility when estimating realized return correlations, in contrast to the GARCH(1,1)-DCC IMA model of Eqs. (1) and (3).
} 
regularity conditions, consistency of those estimates ensures consistency of the estimates stemming from the second step. Engle (2002) showed that these estimates perform well in a variety of situations and provide reasonable empirical results.

\section{Data}

The basic dataset we use in this paper consists of a variety of daily, continuously compounded excess holding-period returns (over three-month Treasury bills) on three asset classes — stocks, Treasury bonds, and corporate bonds whose prices are expected to be affected by four macroeconomic announcements: the Target Fed Funds rates, the Consumer Price Index (CPI), the Unemployment Rate, and the Nonfarm Payroll Employment. Excess stock holding-period returns (including distributions) are computed for the CRSP value-weighted portfolios made of NYSE and AMEX stocks $\left(r_{t}^{n y x}\right)$ and of NASDAQ stocks $\left(r_{t}^{n a q}\right)$. We calculate holding-period returns on Treasury bonds using the constant-maturity five-year, ten-year, and thirty-year time series of interest rates, constructed by the U.S. Treasury from yields on actively traded issues. These rates are converted into excess five-year $\left(r_{t}^{5 y}\right)$, ten-year $\left(r_{t}^{10 y}\right)$, and thirty-year $\left(r_{t}^{30 y}\right)$ holding-period returns on hypothetical par bonds with the corresponding maturity, as in Jones et al. (1998). A similar procedure is employed to compute excess holding-period returns for two portfolios of corporate bonds, one made of Aaa-rated $\left(r_{t}^{a a a}\right)$ and the other made of Baa-rated $\left(r_{t}^{b a a}\right)$ U.S. corporate bonds, with maturity equal to or greater than twenty years, from Moody's Investors Service. ${ }^{16}$ Aaa-rated bonds carry the smallest degree of investment risk. Baa-rated bonds are neither highly protected nor poorly secured, and are generally deemed to have some speculative characteristics. Our sample covers a period of roughly 16 years, from January 3, 1986 (the first day for which daily Baa portfolio yields become available) to February 14, 2002 (the last day for which constant-maturity thirty-year Treasury bond yields are available).

Summary statistics for these series are reported in Table 1. Returns are in percentage, i.e., were multiplied by 100. Not surprisingly, given the growth experienced by the U.S. stock market in the past three decades, the mean excess returns $r_{t}^{n y x}$ and $r_{t}^{n a q}$ are positive, significant, and the highest among the asset classes under examination. Excess bond returns are positive as well, and increasing with maturity and likelihood of default. Daily excess returns are also characterized by little or no skewness, strong and significant

\footnotetext{
${ }^{16}$ For these two portfolios, we assume that the hypothetical par corporate bonds have a maturity of 20 years.
} 
leptokurtosis, and small positive autocorrelation $\left(\widehat{\rho}_{1}>0\right)$. Finally, the LjungBox portmanteau test for up to the fifth-order serial correlation, $L B(5)$, strongly rejects the null hypothesis that excess holding-period returns on stocks, Treasury, highest-grade (Aaa), and medium-grade (Baa) securities are white noise.

We assemble a database of significant macroeconomic announcements over our sample interval. We collect information on all meetings of the Federal Open Market Committee (FOMC) from Bloomberg. In particular, we focus on target Fed Funds rate decisions, which represent the most explicit public disclosure by the Federal Reserve of its stance of monetary policy over the sample period. By law, the FOMC must meet at least 4 times a year, but it has held a minimum of 8 scheduled meetings per year since 1981 . Nonetheless, Bomfim and Reinhart (2000) observe that more than $75 \%$ of changes in the intended Fed Funds rate from 1989 to one993 occurred between those meetings. Furthermore, until the end of 1993, the Federal Reserve took the vast majority of its interest rate decisions in the afternoon, when the Fed Funds market in New York was virtually closed, and declared them by conducting open-market operations the next day. However, since March 28, 1994, the Fed Funds rate has been released regularly at 2:15 p.m. Eastern Standard Time (EST). We control for this delay by shifting the "effective" Fed Funds announcement date by one day until then. ${ }^{17}$

Real-time data (i.e., as reported in the original press releases) and dates on CPI, Nonfarm Payroll, and Unemployment monthly announcements are from the Bureau of Labor Statistics (BLS). The monthly news releases containing CPI data $\left(c p i_{\tau}\right.$, in percentage in Table 2$)$ are usually made available to the public at 8:30 a.m. EST of any day of the second full week of the month following the Tuesday of the week containing the $13^{\text {th }}$ of the previous month. News releases of monthly changes in nonfarm payroll $\left(\right.$ pay $_{\tau}$, in thousands in Table 2) and unemployment $\left(u n e_{\tau}\right.$, in percentage in Table 2) instead come (again at 8:30 a.m. EST) about three weeks after the calendar week (Sunday through Saturday) which includes the $12^{\text {th }}$ day of the previous month.

We classify these economic announcements according to their sign and to whether their content was anticipated by the market. ${ }^{18}$ For that purpose,

\footnotetext{
${ }^{17}$ For more on the timing discrepancy between FOMC announcements and the end of trading in the Fed Funds market, see Kuttner (2001) and Bernanke and Kuttner (2005).

${ }^{18} \mathrm{We}$ do so for $i$ ) these criteria do not require a subjective judgement by the econometrician and ii) the resulting classifications are not too coarse to detect significant announcement effects. Consistently, we do not classify news based on the (absolute or relative) size of their surprise component, since market participants' perception of the magnitude of such surprise is more likely to depend on market conditions in proximity of news arrivals
} 
we use the database of forecasts compiled by International Money Market Services (MMS). Over the past two decades, MMS has surveyed dozens of economists and money managers, collecting their forecasts for a broad range of macroeconomic variables. ${ }^{19}$ Consistent with the existing literature on macroeconomic news arrivals (e.g., Balduzzi et al., 2001; Andersen et al., 2003, 2004), we define each announcement a surprise if its absolute difference with respect to the "market consensus," the corresponding median forecast, is big, i.e., greater than some predetermined threshold. ${ }^{20}$ We use a similar approach for the target rate decisions by the Federal Reserve. Nonetheless, we measure the corresponding market expectations using the thirty-day interest rate futures contract traded on the Chicago Board of Trade (CBOT), since changes in the Fed funds futures rate, an intuitive aggregation of market-wide policy expectations, have been shown to represent more efficient predictors of FOMC's target rate changes. ${ }^{21}$ We employ the algorithm devised by Kuttner (2000) to estimate the one-day rate surprise from the one-day change in the spot-month futures rate around FOMC announcements. Yet, because CBOT futures prices are available only from October 3, 1988, we use MMS forecasts for the first three years of the sample.

According to Table 2, there were 165 FOMC meetings over our sample period. The Federal Reserve decided much less frequently to increase the Fed Funds rate $\left(\mathrm{fed}_{\tau}\right.$, in percentage in Table 2$)$ than to either leave it unchanged or cut it. About $43 \%$ of all rate decisions (and $59 \%$ of rate increases) were unexpected by the market. The CPI series suggests an annual inflation rate of $3 \%$ between 1986 and 2002. Not surprisingly, given the behavior of the U.S. economy over the last two decades, CPI deflation was much less common $\left(c p i_{t} \leq 0\right.$ only 20 times), and went almost always undetected by the market. Recessions were of shorter length $\left(u n e_{\tau}>0\right.$ in 67, and $p a y_{\tau} \leq 0$ in 40, of

than on statistical benchmarks (e.g., their conditional or unconditional mean or median).

${ }^{19}$ MMS surveys are conducted via telephone every last Friday prior to each news announcement, and the resulting median forecasts are released during the following week. According to several studies of their information content (e.g., Urich and Wachtel, 1984; Balduzzi et al., 2001), MMS expectations are generally unbiased and less noisy estimates of the corresponding realized macroeconomic variables than those generated by extrapolative models (e.g., Figlewski and Wachtel, 1981). For a more detailed description of the MMS database and its properties, see Andersen et al. (2003, 2004).

${ }^{20}$ More specifically, we use a threshold of 5 basis points for $f e d_{\tau}, \mathrm{cpi}_{\tau}$, and $u n e_{\tau}$, and of 20,000 jobs for $p^{2} y_{\tau}$. The results that follow were not meaningfully affected by alternative thresholds.

${ }^{21}$ Krueger and Kuttner (1996), Bomfim and Reinhart (2000), and Kuttner (2001) explored the properties of various proxies for market expectations of FOMC rate changes implied by Fed funds future rates. Piazzesi and Swanson (2004) find that forecasts from one-day changes in Fed funds futures rates are the least affected by biases induced by time-varying risk premia. 
194 BLS press releases) and generally exhibited greater per month intensity than expansions, but both were equally difficult to predict on average.

\section{The basic results}

We start our analysis by estimating the model of Eqs. (1) and (3), first over our entire sample of macroeconomic announcements and then for each of them separately, according to the procedure described in Section 3. More specifically, Panel A of Tables 3 and 4 report QML estimates (and robust $t$-statistics) of selected parameters of Eqs. (1) and (3), respectively, when we replace $I_{t}^{e}(k)$ with dummy variables $I_{t}(k)$ equal to one if any of the surprise economic events described in Table 1 took place at time $t+k$ (either $I_{t}^{\text {fed }}(k)=$ $1, I_{t}^{c p i}(k)=1, I_{t}^{\text {une }}(k)=1$, or $I_{t}^{\text {pay }}(k)=1$ ), and zero otherwise. Panel B of Tables 3 and 4 instead report the same QML estimates for each surprise announcement. The inclusion of dummies to control for day-of-the-week effects or the day-level clustering of other macroeconomic announcements (e.g., Jones et al., 1998; Kim et al., 2004) did not significantly affect our inference, either qualitatively or quantitatively.

Tables 3 and 4 reveal a significant dichotomy between the reaction of the U.S. stock and bond markets to economic news. Indeed, conditional stock return volatility is somewhat lower the day before $\left(\delta_{i}(1)<0\right)$, and significantly higher the day of their arrival (88\% higher for the NYSE-AMEX and $31 \%$ higher for the NASDAQ), consistent with the "calm before the storm" conjecture described in Section $2(C(1))$. In contrast, we find that the coefficients $\delta_{i}(1)$ are significantly positive for conditional government and corporate bond return volatility. In particular, the day before the release of macroeconomic news, excess holding-period return volatility actually increases by a minimum of $63 \%$ for Aaa-rated long-term corporate bonds to a maximum of $153 \%$ for five-year Treasury bonds. This suggests that there is considerable increase in uncertainty among bond market participants in anticipation of the release of macroeconomic news. This "storm before the calm" effect is only partially short-lived, since the contemporaneous coefficients $\delta_{i}(0)$, albeit significantly negative (at the $1 \%$ level), are of much lower magnitude (e.g., $\delta_{i}(0)=-0.561$ for five-year Treasury bonds), while $\delta_{i}(-1)$ is either small, negative, and weakly significant, or zero. Stock return volatility in the NYSE-AMEX instead declines appreciably after the announcements $\left(\delta_{i}(-1)=-0.246\right.$ in Table 3$)$, as stated in $C(3)$. The above evidence differs from earlier results by Jones et al. (1998) on a similar set of actual (rather than unexpected) announcements but is compatible with the arguments summarized in $C(2)$ : In the U.S. bond market, any additional in- 
formation stemming from economic news does not appear to augment bond price fluctuations, i.e., these news appear to induce (at least partial) resolution of uncertainty and/or disagreement among bond market participants.

Further insight comes from the analysis of the separate impact of each macroeconomic announcement on conditional return volatility, reported in Panel B of Table 3. As expected (and articulated in $C(4)$ ), the reaction of both stock and bond markets to the target rate decisions by the Federal Reserve is generally different from what we found for any other event. Indeed, the reaction of these markets close to when the Fed announces its target rate is both less economically and statistically significant. For example, when significant, the estimated positive shocks to the conditional return volatility of corporate securities around these announcements are less persistent than across all events (i.e., the absolute estimates for $\delta_{i}^{f e d}(-1)$ are larger than those for $\delta_{i}(-1)$ in Panel A of Table 3$)$. The arrival of employment news has the greatest impact on the government bond market, especially before their release, while CPI news has the lowest; the corresponding effect on corporate bonds, although of same sign, is of somewhat smaller scale. Interestingly, nonfarm payroll surprises, although released simultaneously with unemployment numbers, are preceded and accompanied by relatively more pronounced volatility shocks. This evidence is consistent with some recent studies (e.g., Andersen et al., 2004; Pasquariello and Vega, 2005) suggesting that nonfarm payroll has the greatest information content among all public signals of the state of the U.S. economy available to investors and speculators. The milder reaction of both government and corporate bonds to CPI surprises may instead stem from the relative stability of inflation expectations and the Fed's significant credibility in fighting inflation over our sample period 1986-2002.

The absolute magnitude of $\delta_{i}(1)$ and $\delta_{i}(0)$ is decreasing in the maturity of the bond portfolios and increasing in the likelihood of default, as proxied by the Moody's ratings. Greater sensitivity of corporate bonds of poorer quality to the business cycle (e.g., Gertler and Lown, 2000) may explain the latter. The notion that five-year Treasury bonds are the most liquid (e.g., Brandt and Kavajecz, 2004; Goldreich et al., 2005) may instead explain the former, since we would expect the intensity of information gathering and portfolio rebalancing induced by the news arrivals to be greater for more liquid securities. $^{22}$ Alternatively, mean reversion in short-term interest rates (e.g., Chapman and Pearson, 2000 and references therein) may lead to a weaker impact of an information shock on longer-term bonds, since any impact of

\footnotetext{
${ }^{22}$ E.g., Chowdhry and Nanda (1991). Yet, shorter-maturity bonds are also less sensitive to fluctuations of interest and inflation rate expectations potentially induced by those news. According to Panel B in Table 3, this effect is weaker than the maturity (or liquidity) effect.
} 
such shocks on the short end of the yield curve is expected to die out for its long end.

At this preliminary stage of our analysis, we find strong evidence of a positive relation between the risk premium of each of the asset classes we study and the risk to which they are exposed on days when surprise macroeconomic events take place. More specifically, Panel A of Table 3 shows that mean excess holding-period returns are higher for stocks and lower for bonds during macroeconomic announcements, and that the corresponding estimated coefficient $\gamma_{i}(0)$ is of the same sign as the estimated contemporaneous coefficients $\delta_{i}(0)$ in Eq. (1) for conditional return volatility. These results differ from those of Jones et al. (1998), since their analysis of actual (rather than unexpected) macroeconomic releases suggested that bonds earn higher (and not lower) returns in response to their arrival. Hence, the identification of surprise announcements is critical to the understanding of their impact on the first (and second) moment of stock and bond holding-period returns. The observed decline in bond risk premia is increasing in their maturity (hence decreasing in their liquidity) and (weakly) in the quality of the issuers. The effect on stock risk premia disappears when each event is considered separately. The risk premium for bond returns is instead (economically and statistically) significant only in correspondence with payroll announcements (at the five-year and ten-year Treasury maturity) and CPI news releases (for thirty-year government and corporate bonds), in Panel B of Table 3.

As discussed earlier, within each asset class, the stock markets display the greatest heterogeneity of responses to surprise macroeconomic announcements (CPI, payroll, and unemployment). Indeed, the impact of their arrival on NASDAQ conditional return and volatility is often economic and/or statistically insignificant. This is not surprising, since most "new economy" companies, whose expected growth rate and equity risk premia are deemed less sensitive to labor or inflation news than to the state of their specific industry, are traded there. Consistently, the decoupling with the NYSEAMEX is not complete, for the estimated effect of target rate decisions by the Federal Reserve is instead similar in sign and magnitude to that on Big Board and AMEX stocks $\left(\delta_{i}^{f e d}(0)=0.681\right.$ and 0.729 for $i=r_{t}^{n y x}$ and $r_{t}^{n a q}$, respectively). Further, target rate decisions have a significant impact only on the most liquid bonds in our sample, the five-year Treasury securities, while the estimated coefficients from Eq. (1) in response to CPI and labor data releases are more homogeneous across government and corporate bonds (e.g., $\delta_{i}^{\text {pay }}(0)$ ranging from -0.484 to -0.753 in Panel B of Table 3 ).

We find an even greater dichotomy between the stock and the bond markets when we estimate the DCC IMA covariance model of Eq. (3). The coefficients reported in Panels A and B of Table 4 suggest that the release of 
our sample of economic announcements is preceded by sharply lower comovement among U.S. stock markets on the previous day $\left(\overline{d_{i}(1)}=-0.786\right)$. This decline is only partially reversed on the day of news arrivals and soon afterward $\overline{\left(d_{i}(0)\right.}=0.301$ and $\left.\overline{d_{i}(-1)}=0.164\right)$, even after controlling for their impact on conditional stock return and return volatility. While the drop in the comovement between NYSE-AMEX and NASDAQ excess returns is relatively homogeneous in intensity and significance, the ensuing contemporaneous increase is concentrated in correspondence with CPI surprises, with a magnitude of about $120 \%$ from pre-announcement levels. The decline in covariance among government bond returns around the release of those news is of more diffuse intensity $\left(\overline{d_{i}(1)}=-0.387\right.$ and $\overline{d_{i}(0)}=-0.712$ in Panel A of Table 4) but similar persistence, since it is not fully reabsorbed the trading day afterward $\left(\overline{d_{i}(-1)}=1.002\right)$. Excess returns on Moody's portfolios of Aaa and Baa-rated corporate bonds weakly decuple on announcement days $\left(\overline{d_{i}(0)}=-0.196\right)$, and more strongly so afterward $\left(\overline{d_{i}(-1)}=-0.506\right)$.

Finally, contrary to the conjecture summarized by $C(5)$, comovement among all asset classes actually decreases in the proximity of all macroeconomic news releases (see Panel B of Table 4). ${ }^{23}$ For example, we find that comovement between stock and government bonds, stocks and corporate bonds, and government and corporate bonds declines on average by $95 \%, 97 \%$, and $60 \%$, respectively, on the announcement dates. Hence, any portfolio rebalancing induced by those news or shifts to the degree of information asymmetry and heterogeneity among traders translates into either more negative or less positive (but not more positive) comovement among the excess holding-period returns in our sample. Indeed, this evidence suggests that most of the macroeconomic announcements in our sample have a greater (and possibly more heterogeneous) impact on assets' expected cash flows and risk premia than on the rates at which future cash flows are discounted, thus inducing lower covariance among their returns.

\section{Asymmetric news impact}

In the previous section, we showed that the arrival of macroeconomic news affected significantly the U.S. equity and bond markets between 1986 and 2002. The sign and magnitude of the impact of their release on the dynamics of asset prices should also depend on their information content. Indeed, the

\footnotetext{
${ }^{23}$ We also estimated the model of Eq. (3) separately for each of the covariance pairs $i$ and $j$ when allowing for specific cross-asset adjustment parameters $\lambda_{i j}^{e}$. The results, available on request from the authors, were similar, both qualitatively and quantitatively, to those reported in Table 4.
} 
effect of "good" or "bad" news on each of the three factors driving asset prices, the risk-free rate of interest, the expected cash flows, and the risk premium, is possibly asymmetric. ${ }^{24}$ For example, Boyd et al. (2004) found that, in the short run, the reaction of stock and bond prices to unemployment news, measured with respect to a statistical model for final release numbers, is state-dependent. The equity market usually responds positively to surprisingly rising unemployment, while Treasury bond prices react to it only during expansions. Similarly, Veronesi (1999) argued that "good" or "bad" news may increase uncertainty when released in "bad" or "good" times, respectively. ${ }^{25}$ Furthermore, it is also possible that the various forms of market frictions and financial constraints described in the literature (e.g., borrowing, short-selling, and wealth constraints) are more binding on investors' behavior following "negative" announcements. These constraints could then affect not only the level of asset returns (e.g., Diether et al., 2002) but also their volatility and comovement (Kyle and Xiong, 2001; Yuan, 2005) differentially in proximity of news arrivals.

We explore those issues in this section by amending the model of Eqs. (1) and (3) to allow for asymmetric effects of news releases. More specifically, we introduce the following $\operatorname{GARCH}(1,1)$ model for conditional return volatility

$$
\begin{aligned}
r_{t}^{i} & =\mu_{i}+\rho_{i} r_{t-1}^{i}+\gamma_{i}^{e}(0,+) I_{t}^{e}(0,+)+\gamma_{i}^{e}(0,-) I_{t}^{e}(0,-)+\varepsilon_{t}^{i} \\
\varepsilon_{t}^{i} & =\sqrt{s_{t}^{i \pm}} e_{t}^{i} \quad e_{t}^{i} \mid \digamma_{t-1} \sim N\left(0, h_{t}^{i}\right) \\
h_{t}^{i} & =\omega_{i}+\alpha_{i}\left(e_{t-1}^{i}\right)^{2}+\beta_{i} h_{t-1}^{i},
\end{aligned}
$$

where $s_{t}^{i \pm}=1+\sum_{k=-1}^{+1} \delta_{i}^{e}(k,+) I_{t}^{e}(k,+)+\sum_{k=-1}^{+1} \delta_{i}^{e}(k,-) I_{t}^{e}(k,-)$, and then model comovement among excess holding returns as

$$
\eta_{t}^{i} \eta_{t}^{j}=s_{t}^{i \pm *} \eta_{t-1}^{i} \eta_{t-1}^{j}+\left(q_{t}^{i j}-\eta_{t}^{i} \eta_{t}^{j}\right)-\lambda^{e} s_{t}^{i \pm *}\left(q_{t-1}^{i j}-\eta_{t-1}^{i} \eta_{t-1}^{j}\right)
$$

where $s_{t}^{i \pm *}=1+\sum_{k=-1}^{+1} d_{i}^{e}(k,+) I_{t}^{e}(k,+)+\sum_{k=-1}^{+1} d_{i}^{e}(k,-) I_{t}^{e}(k,-), \eta_{t}^{i}=$ $\frac{\varepsilon_{t}^{i}}{\sqrt{s_{t}^{i \pm} h_{t}^{i}}}, I_{t}^{e}(k,+)$ are dummy variables equal to one if the Federal Reserve announced a surprise rate increase on day $t+k(e=f e d)$, or if the CPI $(e=c p i)$ or the unemployment rate $(e=u n e)$ was reported at day $t+k$ to have surprisingly increased with respect to the previous month, or if the nonfarm payroll $(e=$ pay) was reported on day $t+k$ to have surprisingly

\footnotetext{
${ }^{24}$ In light of the earlier discussion, we use the terms "good" and "bad" to refer exclusively to the content of the news, rather than to their implications for stock and bond valuations.

${ }^{25}$ Along these lines, Andersen et al. (2004) reported that, during the 1990s, intraday stock, bond, and currency futures returns experienced heterogeneous conditional mean and volatility jumps in presence of "good" or "bad" news.
} 
increased (or to have surprisingly remained unchanged) with respect to the previous month, and zero otherwise; vice versa, $I_{t}^{e}(k,-)$ are dummy variables equal to one if the Federal Reserve announced a surprise rate cut or if rates were surprisingly unchanged on day $t+k(e=f e d)$, or if the CPI $(e=c p i)$ or the unemployment rate $(e=u n e)$ was reported at day $t+k$ to have surprisingly decreased (or stayed unchanged) with respect to the previous month, or if the nonfarm payroll $(e=$ pay) was reported on day $t+k$ to have surprisingly decreased with respect to the previous month, and zero otherwise. Hence, $I_{t}^{f e d}(k,+), I_{t}^{c p i}(k,+), I_{t}^{u n e}(k,+)$, and $I_{t}^{p a y}(k,-)$ are "bad" news dummies, while $I_{t}^{\text {fed }}(k,-), I_{t}^{\text {cpi }}(k,-), I_{t}^{\text {une }}(k,-)$, and $I_{t}^{\text {pay }}(k,+)$ are "good" news dummies.

We estimate the model of Eqs. (4) and (5) according to the QML procedure described in Section 3 and report the ensuing coefficients in Table 5 for conditional returns and volatility and in Table 6 for return covariances. Our results reveal a significant degree of asymmetry in the response of the U.S. financial markets to the arrival of macroeconomic news of positive versus negative information content. More specifically, Table 5 shows that the absolute magnitude of the effects of news releases on returns and return volatility described in Section 5 is generally greater when the news are bad (especially worse than expected employment news, i.e., $I_{t}^{\text {une }}(k,+)$, and $\left.I_{t}^{p a y}(k,-)\right)$ : Conditional stock (bond) return volatility rises more sharply the day of (before), and drops more sharply the day after (of) their release. For instance, we find that the conditional volatility of five-year Treasury bond returns increases by $300 \%$ the day before, and then declines by $79 \%$ the day of the release of "bad" unemployment news, versus an increase of $178 \%$ and subsequent decline by $75 \%$ in correspondence with an unexpected decrease in unemployment. CPI data represent the sole exception, since such dichotomous effect of their arrival takes place only in the proximity of surprise inflation. On the other hand, we cannot reject the "storm before the calm" conjecture $C(2)$ described in Section 2 for both corporate and government securities, i.e., we find no evidence of decoupling between the dynamics of conditional stock and bond return volatility in the proximity of unexpected deflation news releases $\left(I_{t}^{c p i}(k,-)\right)$. Overall, this evidence suggests that negative macroeconomic news are more likely to induce greater uncertainty in the U.S. stock and bond markets.

Yet, this uncertainty does not necessarily translate into greater risk premia. Indeed, when examining estimates for the contemporaneous impact of target rate news on conditional excess returns $\left(\gamma_{i}^{e}(0,+)\right.$ and $\gamma_{i}^{e}(0,-)$ in Eq. (4)), we find that unexpected rate cuts by the Federal Reserve have a positive, statistically and economically significant impact on mean excess stock returns (an increase of 33 basis points for the NYSE-AMEX and 40 
basis points for the NASDAQ), albeit being followed by lower conditional volatility the next business day. Interestingly, inflation (deflation) surprises, which generally accompany a growing (slowing) economy and may lead to future target rate increases (cuts) instead, also significantly increase (decrease) mean excess NYSE-AMEX returns (by 15 and 58 basis points, respectively) and decrease (increase) their conditional volatility. Hence, in both cases, the effect on the discount rate for future cash flows appears to dominate any impact on expected cash flows, their perceived riskiness, and the state of the economy. Table 5 further reveals that only unexpected negative payroll numbers and inflation have a significant impact on mean Treasury and corporate bond holding-period returns, respectively. These effects are consistent with $C(6)$ of Section 2, i.e., of negative sign $\left(\gamma_{i}^{\text {pay }}(0,-)<0\right.$ and $\left.\gamma_{i}^{c p i}(0,+)<0\right)$, and follow the significantly greater return volatility induced by those "bad" news the day before their announcement $\left(\delta_{i}^{\text {pay }}(1,-)>0\right.$ and $\left.\delta_{i}^{c p i}(1,+)>0\right)$.

Finally, the differential information content of macroeconomic news has little impact on the direction and intensity of excess comovement across asset classes induced by their arrival. However, the estimates of the DCC IMA model of Eq. (5) in Table 6 display significant differences in sign and magnitude of the impact of the release of good or bad news on intra-asset class covariances, especially in proximity of the release of CPI data. For example, the comovement between NYSE-AMEX and NASDAQ holding-period returns increases by roughly $110 \%$ on days when unexpected deflation news are released $\left(d_{i}^{c p i}(0,-)=1.092\right)$ but is mostly unchanged $\left(d_{i}^{c p i}(0,+)\right.$ is statistically indistinguishable from zero) in correspondence with unexpected inflation news. Lower comovement among classes of stock, government and corporate bond returns usually precedes inflation news, but is quickly reabsorbed after their release. We instead estimate significantly and persistently lower return covariances in proximity of deflation news. This suggests that the these arrivals are more likely to induce a wave of rebalancing activity among the asset classes in our sample. Along the same lines, target rate increases induce lower comovement among high-rated and low-rated corporate bonds than rate cuts, i.e., are more likely to induce investors to shift their portfolios away from low-quality issuers.

\section{Market reaction to expected information}

The conjectures listed in Section 2 stem from the underlying assumption that the macroeconomic announcements in our sample represent indeed "news." We made this assumption operational in our empirical analysis by concentrating only on unexpected announcements, i.e., different in sign and magnitude 
from market consensus. This procedure is widely adopted in the literature. ${ }^{26}$ If information transmission is in fact the basic channel through which news releases affect the process of price formation in financial markets, then anticipated announcements should have no discernible impact on conditional returns, return volatility, and comovement. Hence, evidence of the contrary would suggest that the many nuances and frictions of the trading mechanism are important determinants of (excess) volatility and comovement within and among asset returns in the U.S. stock, Treasury and corporate bond markets.

We explore this possibility by estimating the model of Eqs. (1) and (3) for the subset of expected macroeconomic announcements in our sample, according to the definitions in Section 4. The resulting parameters, reported in Table 7 for various $\operatorname{GARCH}(1,1)$ representations and in Table 8 for the corresponding DCC IMA exponential smoothers, lead us to strongly reject the conjecture $C(7)$ that anticipated macroeconomic announcements should have no impact on the fluctuations of corporate and government security returns. In particular, we find that news arrivals of expected content are often preceded by increasing, and then accompanied by declining conditional bond return volatility (e.g., $\delta_{i}(1)=0.246$ and $\delta_{i}(1)=-0.288$ for $i=r_{t}^{10 y}$ in Panel A of Table 7). Yet, in most cases, these patterns do not translate into greater mean excess holding-period returns. Expected announcements do not generally increase the uncertainty in the stock market, but when they do so (in correspondence with expected target rate decisions by the Federal Reserve for the NYSE-AMEX, and nonfarm payroll numbers for the NASDAQ), equity risk premia rise by roughly 20 basis points on average on the day they took place.

This evidence, novel to the literature studying the U.S. financial markets, is consistent with a recent study by Andersen et al. (2003) which shows that the release of most macroeconomic data tends to boost exchange rate volatility, regardless of their information content. These findings offer support to the possibility raised by many recent theoretical studies (e.g., Fleming et al., 1998; Kyle and Xiong, 2001; Kodres and Pritsker, 2002; Yuan, 2005) that the trading activity of investors and speculators (e.g., portfolio rebalancing, market sentiment) and/or the existence of frictions and constraints to its functioning (e.g., limits to borrowing and short-selling) may also significantly affect asset prices. Indeed, novel as well to this literature is the evidence in Table 8, which shows that even the anticipated macroeconomic announcements in our sample induce significantly lower return comovement

\footnotetext{
${ }^{26}$ Some recent examples are Bomfim and Reinhart (2000), Andersen et al. (2003, 2004), Bomfim (2003), Brandt and Kavajecz (2004), and Green (2004). Alternative procedures involve the specification of statistical forecasting models to construct announcement surprises, as in Boyd et al. (2004).
} 
within and across asset classes, albeit less so than around news arrival dates. Overall, these results suggest that, while stock and bond prices in the U.S. financial markets do appear to be driven by fundamentals (consistently with the previous analysis in Sections 5 and 6), excess volatility and comovement play an important role in their dynamics and interaction.

\section{Conclusions}

The analysis of the extent to which prices in financial markets incorporate fundamental information is central to the theoretical and empirical finance literature. The traditional notion of market efficiency requires that information about asset payoffs should be quickly and fully reflected in asset prices and drive their dynamics. Much prior research has examined the links between financial and real variables by studying the effects of the disclosure of macroeconomic information on stock and bond markets. Yet, this work has often either ignored the implications of these announcements for the joint distribution of stock and bond returns, focused only on their first or second moments, or failed to identify the anticipated portion of those news releases. More recent studies have also raised the possibility that a significant portion of asset return volatility and covariation may instead be deemed "excessive." In particular, these studies have emphasized the increasing importance of the trading activity of investors and speculators to explain return (co)movements.

Our paper contributes to this debate by providing a comprehensive analysis of the impact of both the unexpected and expected components of important U.S. macroeconomic news releases on the process of price formation in the three most important U.S. financial markets, for equity, government bonds, and corporate bonds. For that purpose, we developed an extension of the DCC IMA model of Engle (2002) that allows us to simultaneously (yet parsimoniously) identify the effects of news arrivals on conditional mean

returns, return volatility, and return covariance. We estimated different versions of this model over our sample of announcements of target rate decisions by the Federal Reserve, CPI, Unemployment, and Nonfarm Payroll data from the Bureau of Labor Statistics between 1986 and 2002.

We find that the arrival of macroeconomic news has a statistically and economically significant impact on the U.S. financial markets, but also that this impact varies greatly across asset classes. Conditional stock return volatility decreases on the trading day before, increases on the day when the announcements are made, and subsequently decreases, along the lines with the "calm before the storm" hypothesis of Jones et al. (1998). Conditional bond return volatility instead increases when the news are released, and declines 
afterward. This effect is stronger for portfolios of bonds of shorter maturity (the most liquid and sensitive to the mean-reverting nature of the short rate drift) or more likely to default. Consistently, contemporaneous risk premia decrease for stocks and increase for bonds. The estimated shifts in volatility appear to be persistent in the short run, i.e., do not offset each other completely over a three-day event window around the announcements. These effects are also strongly asymmetric: Their sign and magnitude depend on whether the macroeconomic information released represented "good" versus "bad" news. This evidence often differs from earlier studies in which the surprise component of the announcements was not identified (e.g., Jones et al., 1998). Somewhat surprisingly, we also find that even the release of expected information is preceded and accompanied by a similar, significant impact on the dynamics of both Treasury and corporate bond portfolio returns.

Finally, our estimates paint a complex picture of the interaction between asset returns in proximity of news releases. Yet, they offer little or no support to the notion that the arrival of these news is accompanied by greater comovement among asset returns. Indeed, return comovement within and across stock and bond markets generally decreases in correspondence with those announcements, albeit less so when anticipated by the market. These findings suggest that the heterogeneous impact of news on investors' trading activity and assets' expected cash flows and risk premia (rather than on the rates at which future cash flows are discounted) may generate excessive volatility and negative covariance among their returns.

Ultimately, this study reported a wide array of novel empirical evidence — stemming from a robust yet manageable methodology — on the effects of the release of macroeconomic news on the moments of returns in U.S. equity, government bond, and corporate bond markets. We suggested that much of this evidence is consistent with existing theoretical arguments in the literature. Nonetheless, we hope that our work may stimulate further research on a unifying theory to explain these fascinating stylized facts.

\section{References}

[1] Andersen, T., Bollerslev, T. (1997). Intraday Periodicity and Volatility Persistence in Financial Markets. Journal of Empirical Finance, 4, 115158.

[2] Andersen, T., Bollerslev, T. (1998). Deutsche Mark-Dollar Volatility: Intraday Activity Patterns, Macroeconomic Announcements, and Longer Run Dependencies. Journal of Finance, 53, 219-265. 
[3] Andersen, T., Bollerslev, T., Diebold, F., Labys, P. (2003). Modeling and Forecasting Realized Volatility. Econometrica, 71, 579-625.

[4] Andersen, T., Bollerslev, T., Diebold, F., Vega, C. (2003). Micro Effects of Macro Announcements: Real-Time Price Discovery in Foreign Exchange. American Economic Review, 93, 1132-1145.

[5] Andersen, T., Bollerslev, T., Diebold, F., Vega, C. (2004). Real Price Discovery in Stock, Bond, and Foreign Exchange Markets. Working Paper, Northwestern University.

[6] Balduzzi, P., Elton, E., Green, C. (2001). Economic News and Bond Prices: Evidence from the U.S. Treasury Market. Journal of Financial and Quantitative Analysis, 36, 523-543.

[7] Barberis, N., Shleifer, A., Wurgler, J. (2005). Comovement. Journal of Financial Economics, 75, 283-317.

[8] Bernanke, B., Kuttner, K. (2005). What Explains the Stock Market's Reaction to Federal Reserve Policy? Journal of Finance, forthcoming.

[9] Bollerslev, T. (1986). Generalized Autoregressive Conditional Heteroskedasticity. Journal of Econometrics, 31, 307-327.

[10] Bollerslev, T. (1990). Modelling the Coherence in Short-Run Nominal Exchange rates: A Multivariate Generalized ARCH Approach. Review of Economics and Statistics, 72, 498-505.

[11] Bollerslev, T., Engle, R., Wooldridge, J. (1988). A Capital Asset Pricing Model with Time Varying Covariances. Journal of Political Economy, 96, 116-131.

[12] Bollerslev, T., Wooldridge, J. (1992). Quasi-Maximum Likelihood Estimation and Inference in Dynamic Models with Time-Varying Covariances. Econometric Reviews, 11, 143-172.

[13] Bomfim, A. (2003). Pre-announcement Effects, News Effects, and Volatility: Monetary Policy and the Stock Market. Journal of Banking $\&$ Finance, 27, 133-151.

[14] Bomfim, A., Reinhart, V. (2000). Making News: Financial Market Effects of Federal Reserve Disclosure Practices. Working Paper, IMF. 
[15] Boyd, J., Hu, J., Jagannathan, R. (2004). The Stock Market's Reaction to Unemployment News: Why Bad News is Usually Good for Stocks? Journal of Finance, forthcoming.

[16] Brandt, M., Kavajecz, K. (2004). Price Discovery in the U.S. Treasury Market: The Impact of Order Flow and Liquidity on the Yield Curve. Journal of Finance, forthcoming.

[17] Chapman, D., Pearson, N. (2000). Is the Short Rate Drift Actually Nonlinear? Journal of Finance, 55, 355-388.

[18] Chen, N., Roll, R., Ross, S. (1986). Economic Forces and the Stock Market. Journal of Business, 59, 383-403.

[19] Chowdhry, B., Nanda, V. (1991). Multimarket Trading and Market Liquidity. Review of Financial Studies, 4, 483-511.

[20] Christiansen, C., Ranaldo, A. (2005). Realized Bond-Stock Correlation: Macroeconomic Announcement Effects. Working Paper, Swiss National Bank.

[21] Connolly, R., Wang, A. (2000). On Stock Market Return Co-movements: Macroeconomic News, Dispersion of Beliefs, and Contagion. Working Paper, University of North Carolina at Chapel Hill.

[22] Diether, K., Malloy, C., Scherbina, A. (2002). Differences of Opinion and the Cross Section of Stock Returns. Journal of Finance, 57, 2113-2141.

[23] Engle, R. (1995). ARCH: Selected Readings. Oxford University Press, New York.

[24] Engle, R. (2002). Dynamic Conditional Correlation - A Simple Class of Multivariate GARCH Models. Journal of Business and Economic Statistics, 20, 339-350.

[25] Engle, R., Bollerslev, T. (1986). Modelling the Persistence of Conditional Variance. Econometric Reviews, 5, 81-87.

[26] Engle, R., Kroner, K. (1995). Multivariate Simultaneous Generalized ARCH. Econometric Theory, 11, 122-150.

[27] Engle, R., Lilien, D., Robins, R. (1987). Estimating Time-Varying Risk Premia in the Term Structure: The ARCH-M Model. Econometrica, 55, 391-407. 
[28] Fama, E. (1971). Risk, Return, and Equilibrium. Journal of Political Economy, 79, 30-55.

[29] Figlewski, S., Wachtel, P. (1981). The Formation of Inflationary Expectations. Review of Economics and Statistics, 63, 1-10.

[30] Fleming, J., Kirby, C., Ostdiek, B. (1998). Information and Volatility Linkages in the Stock, Bond, and Money Markets. Journal of Financial Economics, 49, 111-137.

[31] Fleming, J., Remolona, E. (1999). Price Formation and Liquidity in the U.S. Treasury Market: The Response to Public Information. Journal of Finance, 54, 1901-1915.

[32] Forbes, K., Rigobon, R. (2002). No Contagion, Only Interdependence: Measuring Stock Market Co-Movements. Journal of Finance, 57, 22232261.

[33] Foster, F., Viswanathan, S. (1993). The Effect of Public Information and Competition on Trading Volume and Price Volatility. Review of Financial Studies, 6, 23-56.

[34] French, K., Schwert, W., Stambaugh, R. (1987). Expected Stock Returns and Volatility. Journal of Financial Economics, 19, 3-29.

[35] Fuerbringer, J. (2004). The Markets: Stocks \& Bonds; Job Report Sends Stocks and Bonds Sharply Lower. New York Times, May 8, p. B1.

[36] Gertler, M., Lown, C. (2000). The Information in the High Yield Bond Spread for the Business Cycle: Evidence and Some Implications. NBER Working Paper No. 7549.

[37] Goldreich, D., Hanke, B., and Nath, P., 2005, The Price of Future Liquidity: Time-Varying Liquidity in the U.S. Treasury Market, Review of Finance, forthcoming.

[38] Hasbrouck, J., 2004, Economic and Statistical Perspectives on the Dynamics of Trade in Securities Markets, Teaching Notes, Stern School of Business, New York University.

[39] Hirshleifer, D. (2001). Investor Psychology and Asset Pricing. Journal of Finance, 56, 1533-1597.

[40] Jones, C., Lamont, O., Lumsdaine, R. (1998). Macroeconomic News and Bond Market Volatility. Journal of Financial Economics, 47, 315-337. 
[41] Kallberg, J., Liu, C., Pasquariello, P. (2005). An Examination of the Asian Crisis: Regime Shifts in Currency and Equity Markets. Journal of Business, 78, 169-211.

[42] Kallberg, J., Pasquariello, P. (2004). Time-Series and Cross-Sectional Excess Comovement in Stock Indexes. Working Paper, Ross School of Business, University of Michigan.

[43] Karolyi, G., Stulz, R. (1996). Why Do Markets Move Together? An Investigation of U.S.-Japan Stock Return Comovements. Journal of Finance, 51, 951-986.

[44] Kim, S., McKenzie, M., Faff, R. (2004). Macroeconomic News Announcements and the Role of Expectations: Evidence for US Bond, Stock and Foreign Exchange Markets. Journal of Multinational Financial Management, 14, 217-232.

[45] King, M., Wadhwani, S. (1990). Transmission of Volatility between Stock Markets. Review of Financial Studies, 3, 5-33.

[46] Kodres, L., Pritsker, M. (2002). A Rational Expectations Model of Financial Contagion. Journal of Finance, 57, 769-799.

[47] Kroner, K., Ng, V. (1998). Modeling Asymmetric Comovements of Asset returns. Review of Financial Studies, 11, 817-844.

[48] Krueger, J., Kuttner, K. (1996). The Fed Funds Futures Rate as a Predictor of Federal Reserve Policy. Journal of Futures Markets, 16, 865-879.

[49] Kuttner, K. (2001). Monetary Policy Surprises and Interest Rates: Evidence from the Fed Funds Futures Market. Journal of Monetary Economics, 47, 523-544.

[50] Kyle, A., Xiong, W. (2001). Contagion as a Wealth Effect. Journal of Finance, 56, 1401-1440.

[51] Li, L., Engle, R. (1998). Macroeconomic Announcements and Volatility of Treasury Futures. Working Paper, University of California, San Diego.

[52] Lucas, R. (1982). Interest rates and Currency Prices in a Two-Country World. Journal of Monetary Economics, 10, 335-359.

[53] Merton, R. (1973). An Intertemporal Capital Asset Pricing Model. Econometrica, 41, 867-887. 
[54] Nelson, D. (1990). ARCH Models as Diffusion Approximations. Journal of Econometrics, 45, 7-38.

[55] Nelson, D. (1991). Conditional Heteroskedasticity in Asset Returns: A New Approach. Econometrica, 59, 347-370.

[56] Nelson, D., Foster, D. (1994). Asymptotic Filtering Theory for Univariate ARCH Models. Econometrica, 62, 1-41.

[57] Pasquariello, P. (2005). Imperfect Competition, Information Heterogeneity, and Financial Contagion. Review of Financial Studies, forthcoming.

[58] Pasquariello, P., Vega, C. (2005). Informed and Strategic Order Flow in the Bond Markets. Working Paper, Ross School of Business, University of Michigan.

[59] Piazzesi, M., Swanson, E. (2004). Futures Prices as Risk-Adjusted Forecasts of Monetary Policy. NBER Working Paper No. 10547.

[60] Pindyck, R., Rotemberg, J. (1990). The Excess Comovement of Commodity Prices. Economic Journal, 100, 1173-1189.

[61] Pindyck, R., Rotemberg, J. (1993). The Comovement of Stock Prices. Quarterly Journal of Economics, 108, 1073-1104.

[62] Ross, S. (1989). Information and Volatility: The No-Arbitrage Martingale Approach to Timing and Resolution Irrelevancy. Journal of Finance, 44, 1-17.

[63] Shiller, R. (1989). Comovements in Stock Prices and Comovements in Dividends. Journal of Finance, 44, 719-729.

[64] Urich, T., Wachtel, P. The Effects of Information and Money Supply Announcements on Interest Rates. Journal of Finance, 39, 1177-1188.

[65] Veronesi, P. (1999). Stock Market Overreaction to Bad News in Good Times: A Rational Expectations Equilibrium Model. Review of Financial Studies, 12, 975-1007.

[66] Yuan, K. (2005). Asymmetric Price Movements and Borrowing Constraints: A REE Model of Crisis, Contagion, and Confusion. Journal of Finance, 60, 379-411. 


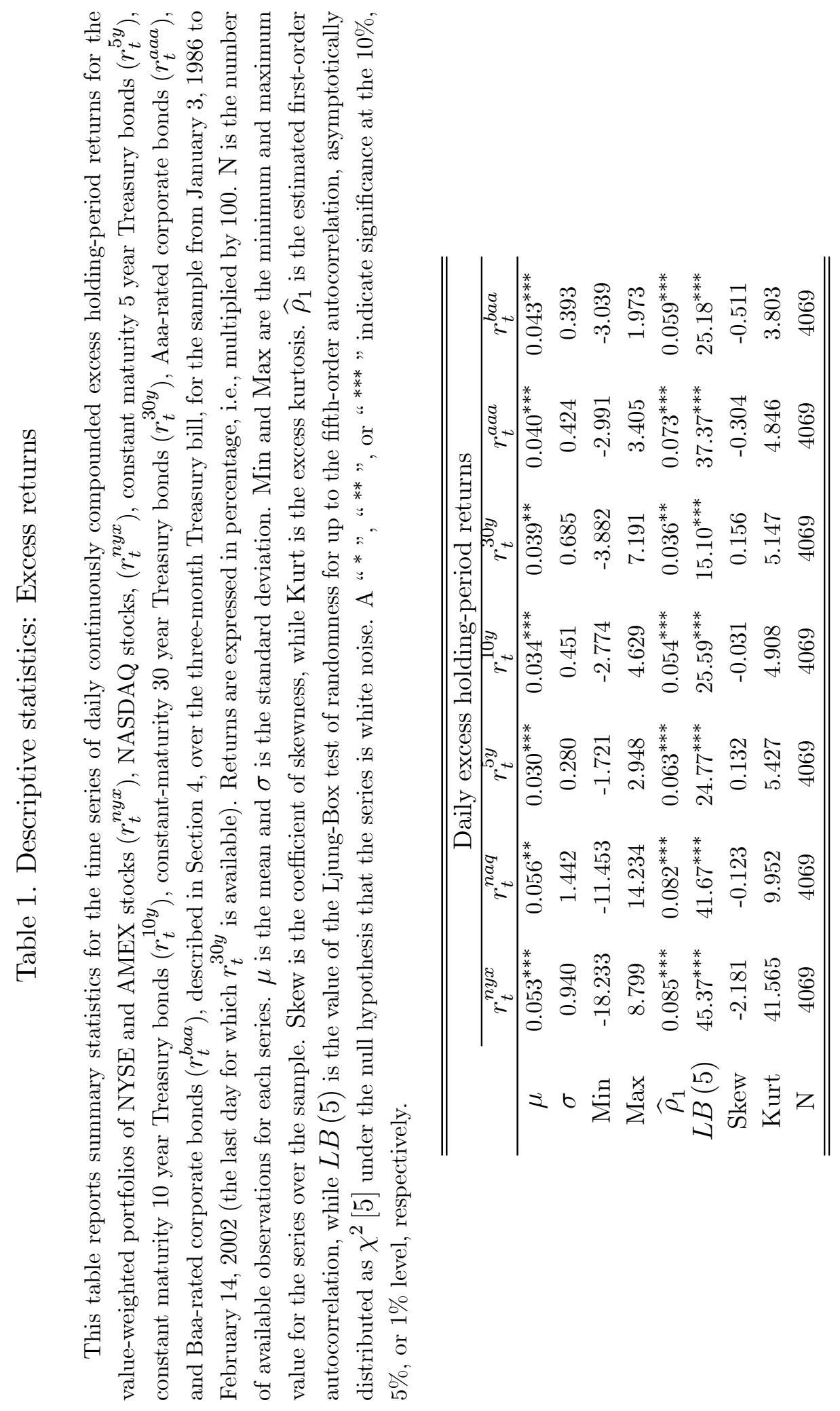




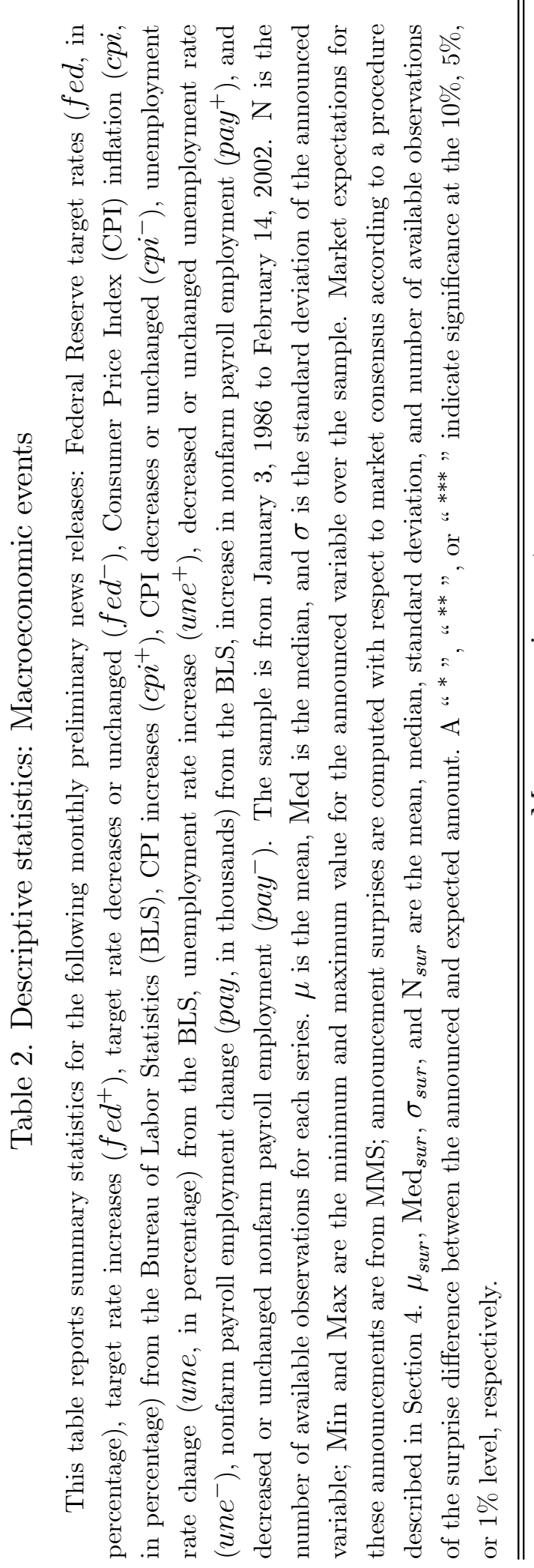

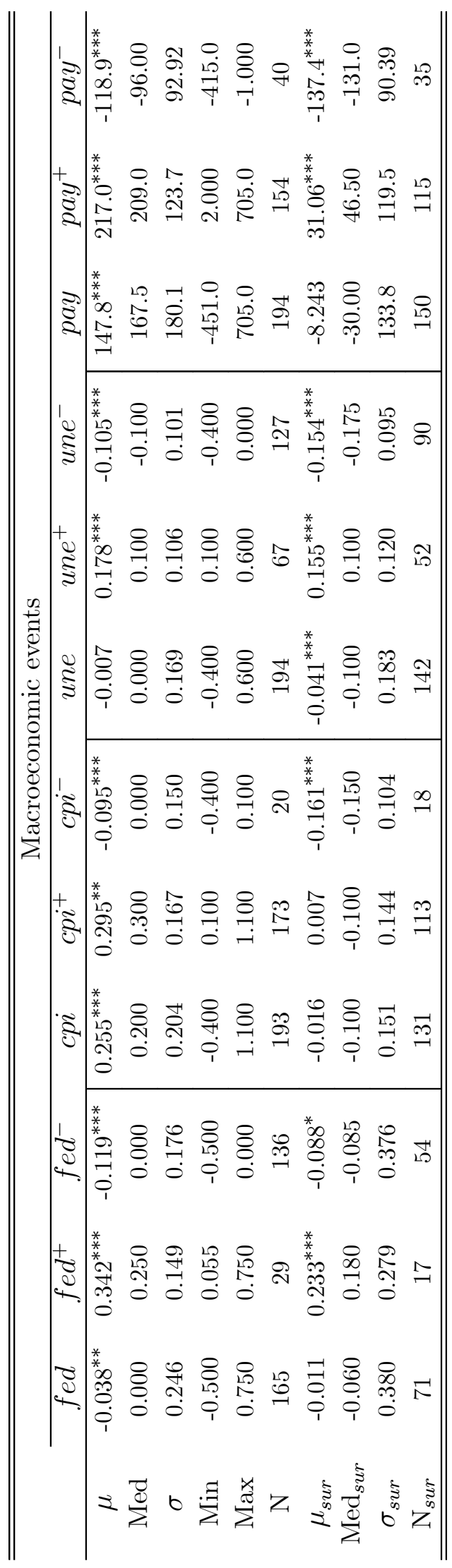


Table 3. GARCH model for excess returns: Surprise events

This table reports quasi-maximum likelihood (QML) estimates (and their robust $t$ statistics (Bollerslev and Wooldridge, 1992)) for the $\operatorname{GARCH}(1,1)$ model of Eq. (1):

$$
\begin{aligned}
r_{t}^{i} & =\mu_{i}+\rho_{i} r_{t-1}^{i}+\gamma_{i}(0) I_{t}(0)+\varepsilon_{t}^{i} \\
\varepsilon_{t}^{i} & =\sqrt{s_{t}^{i}} e_{t}^{i} \quad e_{t}^{i} \mid \digamma_{t-1} \sim N\left(0, h_{t}^{i}\right) \\
h_{t}^{i} & =\omega_{i}+\alpha_{i}\left(e_{t-1}^{i}\right)^{2}+\beta_{i} h_{t-1}^{i},
\end{aligned}
$$

where $\digamma_{t-1}$ denotes the information set, $s_{t}^{i}=1+\sum_{k=-1}^{+1} \delta_{i}(k) I_{t}(k), r_{t}^{i}$ is the daily continuously compounded excess return on asset $i$ (see Section 4 ). In Panel A, $I_{t}(k)=$ 1 if either a surprise Federal Reserve rate change $\left(I_{t}^{f e d}(k)=1\right)$, or a surprise CPI $\left(I_{t}^{c p i}(k)=1\right)$, unemployment $\left(I_{t}^{u n e}(k)=1\right)$, or payroll announcement $\left(I_{t}^{\text {pay }}(k)=1\right)$ was made on day $t+k$ and zero otherwise; in Panel $\mathrm{B}$, we consider each event $e$ separately $\left(I_{t}(k)=I_{t}^{e}(k)\right)$. Returns are in percentage. Eq. (1) is estimated over a sample from January 3, 1986 to February 14, 2002 (i.e., 4069 observations). Log L is the value of the $\log$ likelihood function of Eq. (1) at convergence. A "* ", "** ", or "*** " indicate significance at the $10 \%, 5 \%$, or $1 \%$ level, respectively.

\begin{tabular}{cccccccc}
\hline \hline & \multicolumn{6}{c}{ Panel A: All events } \\
\cline { 2 - 7 } & $r_{t}^{\text {nyx }}$ & $r_{t}^{\text {naq }}$ & $r_{t}^{5 y}$ & $r_{t}^{\text {10y }}$ & $r_{t}^{30 y}$ & $r_{t}^{\text {aaa }}$ & $r_{t}^{\text {baa }}$ \\
\hline$\mu_{i}$ & $0.057^{* * *}$ & $0.065^{* * *}$ & $0.033^{* * *}$ & $0.041^{* * *}$ & $0.051^{* * *}$ & $0.044^{* * *}$ & $0.049^{* * *}$ \\
& 5.00 & 4.91 & 8.14 & 6.20 & 4.96 & 8.26 & 9.10 \\
$\rho_{i}$ & $0.114^{* * *}$ & $0.175^{* * *}$ & $0.074^{* * *}$ & $0.080^{* * *}$ & $0.045^{* * *}$ & $0.095^{* * *}$ & $0.076^{* * *}$ \\
& 6.68 & 10.24 & 4.57 & 4.92 & 2.77 & 5.78 & 4.64 \\
$\gamma_{i}(0)$ & $0.095^{* *}$ & $0.123^{* * *}$ & $-0.040^{* * *}$ & $-0.053^{* *}$ & $-0.068^{* *}$ & -0.023 & $-0.037^{* *}$ \\
& 2.07 & 2.66 & -2.88 & -2.36 & -2.00 & -1.30 & -2.06 \\
\hline$\omega_{i}$ & $0.018^{* * *}$ & $0.037^{* * *}$ & $0.004^{* * *}$ & $0.006^{* * *}$ & $0.011^{* * *}$ & $0.001^{* * *}$ & $0.001^{* * *}$ \\
& 5.14 & 5.73 & 4.26 & 4.55 & 4.17 & 3.38 & 3.58 \\
$\alpha_{i}$ & $0.114^{* * *}$ & $0.147^{* * *}$ & $0.077^{* * *}$ & $0.060^{* * *}$ & $0.043^{* * *}$ & $0.061^{* * *}$ & $0.061^{* * *}$ \\
& 10.80 & 11.31 & 7.37 & 7.46 & 7.07 & 8.24 & 8.17 \\
$\beta_{i}$ & $0.857^{* * *}$ & $0.812^{* * *}$ & $0.872^{* * *}$ & $0.905^{* * *}$ & $0.936^{* * *}$ & $0.941^{* * *}$ & $0.936^{* * *}$ \\
& 64.20 & 47.99 & 42.28 & 63.75 & 86.25 & 115.24 & 106.57 \\
$\delta_{i}(-1)$ & $-0.246^{* * *}$ & -0.053 & $-0.108^{*}$ & $-0.098^{*}$ & -0.048 & $-0.138^{* *}$ & $-0.127^{* *}$ \\
& -4.74 & -0.72 & -1.89 & -1.71 & -0.80 & -2.50 & -2.45 \\
$\delta_{i}(0)$ & $0.879^{* * *}$ & $0.314^{* *}$ & $-0.561^{* * *}$ & $-0.470^{* * *}$ & $-0.432^{* * *}$ & $-0.332^{* * *}$ & $-0.396^{* * *}$ \\
& 5.69 & 2.53 & -15.54 & -11.10 & -9.89 & -5.93 & -8.15 \\
$\delta_{i}(1)$ & $-0.184^{* * *}$ & -0.070 & $1.533^{* * *}$ & $1.105^{* * *}$ & $0.779^{* * *}$ & $0.628^{* * *}$ & $0.827^{* * *}$ \\
& -3.19 & -0.98 & 8.52 & 7.56 & 6.46 & 5.72 & 6.68 \\
\hline Log L & -4853.61 & -5803.54 & -327.09 & -2309.97 & -4065.52 & -1761.91 & -1626.88 \\
\hline \hline
\end{tabular}


Table 3 (Continued).

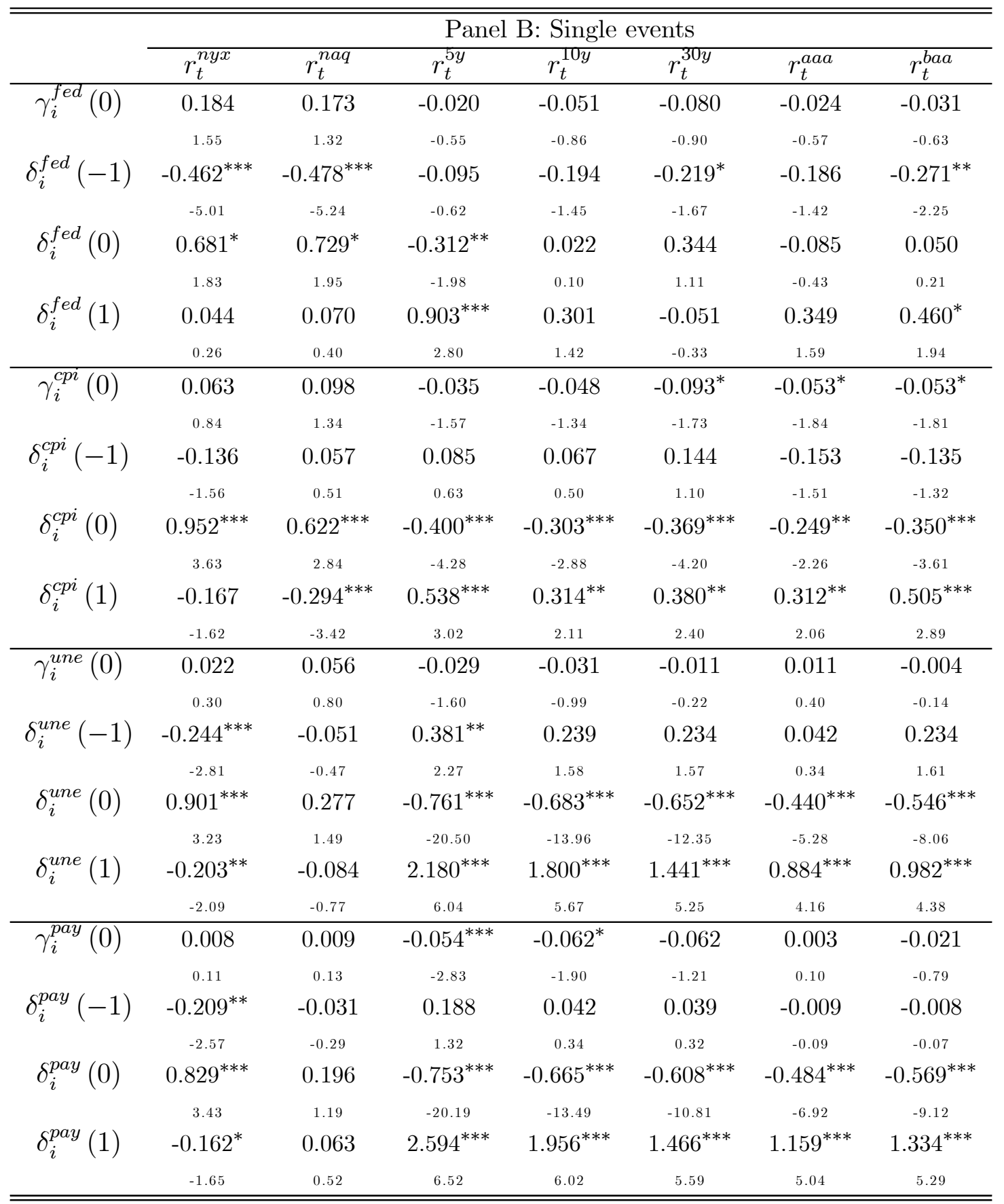




\section{Table 4. DCC IMA model: Surprise events}

This table reports intra and across-asset class averages of quasi-maximum likelihood (QML) estimates (and of their robust $t$-statistics (Bollerslev and Wooldridge, 1992)) for the DCC IMA model of Eq. (3) from the standardized residuals of the $\operatorname{GARCH}(1,1)$ model of Eq. (1):

$$
\eta_{t}^{i} \eta_{t}^{j}=s_{t}^{i *} \eta_{t-1}^{i} \eta_{t-1}^{j}+\left(q_{t}^{i j}-\eta_{t}^{i} \eta_{t}^{j}\right)-\lambda s_{t}^{i *}\left(q_{t-1}^{i j}-\eta_{t-1}^{i} \eta_{t-1}^{j}\right)
$$

where $s_{t}^{i *}=1+\sum_{k=-1}^{+1} d_{i}(k) I_{t}(k)$ and $\eta_{t}^{i}=\frac{\varepsilon_{t}^{i}}{\sqrt{s_{t}^{i} h_{t}^{i}}}$ is the daily standardized error from the expression for $r_{t}^{i}$, the excess return on asset $i$, in Eq. (1). In Panel A, $I_{t}(k)$ is a dummy variable equal to one if either a surprise Federal Reserve rate change took place, or a surprise CPI, unemployment, or payroll announcement was made on day $t+k$ and zero otherwise. In Panel B, Eq. (3) is estimated separately for each surprise event $e$, where $I_{t}^{e}(k)=1$ if a surprise Federal Reserve $(e=f e d)$, CPI ( $\left.e=c p i\right)$, unemployment ( $e=$ une), or payroll ( $e=$ pay) event took place on day $t+k$ and zero otherwise. Returns are expressed in percentage, i.e., multiplied by 100. Eq. (3) is estimated over a sample from January 3, 1986 to February 14, 2002, i.e., over 4069 observations. The Stock category is made of $i=n y x, n a q$; the Govt category is made of $i=5 y, 10 y$, $30 y$; the Corp category is made of $i=a a a$, baa. Averages are calculated for estimates of the dummy coefficients $d_{i}(k)$ among and across asset classes.

\begin{tabular}{|c|c|c|c|c|c|c|c|c|c|}
\hline & \multicolumn{9}{|c|}{ Panel A: All events } \\
\hline & \multicolumn{3}{|c|}{$d_{i}(-1)$} & \multicolumn{3}{|c|}{$d_{i}(0)$} & \multicolumn{3}{|c|}{$d_{i}(1)$} \\
\hline & Stock & Govt & Corp & Stock & Govt & Corp & Stock & Govt & Corp \\
\hline \multirow[t]{2}{*}{ Stock } & 0.164 & -0.065 & -1.445 & 0.301 & -0.945 & -0.965 & -0.786 & -1.038 & -0.957 \\
\hline & 3.28 & 1.10 & -31.90 & 5.20 & -16.66 & -18.37 & -20.29 & -25.00 & -22.83 \\
\hline Govt & & 1.002 & -0.493 & & -0.712 & -0.593 & & -0.387 & -0.461 \\
\hline \multirow{3}{*}{ Corp } & & 12.73 & -9.78 & & -15.41 & -11.56 & & -8.29 & -8.70 \\
\hline & & & -0.506 & & & -0.196 & & & -0.032 \\
\hline & & & -14.89 & & & -5.12 & & & -0.54 \\
\hline
\end{tabular}


Table 4 (Continued).

\begin{tabular}{|c|c|c|c|c|c|c|c|c|c|}
\hline & \multicolumn{9}{|c|}{ Panel B: Single events } \\
\hline & \multicolumn{3}{|c|}{$d_{i}^{f e d}(-1)$} & \multicolumn{3}{|c|}{$d_{i}^{f e d}(0)$} & \multicolumn{3}{|c|}{$d_{i}^{f e d}(1)$} \\
\hline \multirow{3}{*}{ Stock } & Stock & Govt & Corp & Stock & Govt & Corp & Stock & Govt & Corp \\
\hline & -0.600 & -1.007 & -1.124 & -1.915 & -0.815 & -1.013 & -0.875 & -1.200 & -1.098 \\
\hline & -8.02 & -12.66 & -12.43 & -19.05 & -11.20 & -11.85 & -21.26 & -17.86 & -13.56 \\
\hline Govt & & -0.546 & -0.431 & & -0.029 & -0.418 & & -0.548 & -0.564 \\
\hline \multirow{3}{*}{ Corp } & & -7.48 & -5.74 & & -0.30 & -4.30 & & -9.93 & -7.53 \\
\hline & & & -0.253 & & & -0.128 & & & 0.180 \\
\hline & & & -3.14 & & & -1.44 & & & 1.66 \\
\hline & \multicolumn{3}{|c|}{$d_{i}^{c p i}(-1)$} & \multicolumn{3}{|c|}{$d_{i}^{c p i}(0)$} & \multicolumn{3}{|c|}{$d_{i}^{c p i}(1)$} \\
\hline & Stock & Govt & Corp & Stock & Govt & Corp & Stock & Govt & Corp \\
\hline Stock & 0.861 & -0.396 & -1.892 & 1.184 & -0.814 & -0.721 & -0.676 & -1.052 & -0.913 \\
\hline & 7.74 & -1.38 & -31.22 & 8.47 & -14.35 & -12.55 & -15.47 & -13.95 & -15.80 \\
\hline Govt & & 2.200 & -1.309 & & -0.425 & -0.830 & & -0.382 & -0.858 \\
\hline \multirow{5}{*}{ Corp } & & 11.05 & -17.71 & & -8.41 & -14.34 & & -7.36 & -13.92 \\
\hline & & & -0.237 & & & -0.260 & & & 0.017 \\
\hline & & & -4.53 & & & -4.58 & & & 0.24 \\
\hline & \multicolumn{3}{|c|}{$d_{i}^{u n e}(-1)$} & \multicolumn{3}{|c|}{$d_{i}^{u n e}(0)$} & \multicolumn{3}{|c|}{$d_{i}^{u n e}(1)$} \\
\hline & Stock & Govt & Corp & Stock & Govt & Corp & Stock & Govt & Corp \\
\hline \multirow[t]{2}{*}{ Stock } & -0.208 & -0.931 & -1.011 & -0.192 & -1.106 & -0.816 & -1.461 & -1.011 & -1.003 \\
\hline & -3.44 & -17.11 & -22.06 & -3.10 & -12.32 & -13.88 & -21.52 & -15.54 & -15.39 \\
\hline Govt & & -0.691 & -0.476 & & -0.253 & -0.462 & & -1.699 & -1.445 \\
\hline \multirow{5}{*}{ Corp } & & -15.92 & -12.79 & & -4.55 & -6.23 & & -26.32 & -22.84 \\
\hline & & & -0.106 & & & 0.312 & & & -0.224 \\
\hline & & & -1.63 & & & 3.69 & & & -3.87 \\
\hline & \multicolumn{3}{|c|}{$d_{i}^{p a y}(-1)$} & \multicolumn{3}{|c|}{$d_{i}^{p a y}(0)$} & \multicolumn{3}{|c|}{$d_{i}^{p a y}(1)$} \\
\hline & Stock & Govt & Corp & Stock & Govt & Corp & Stock & Govt & Corp \\
\hline \multirow[t]{2}{*}{ Stock } & -0.619 & -0.968 & -0.966 & -1.977 & -0.888 & -1.035 & -1.477 & -0.998 & -0.991 \\
\hline & -14.69 & -20.14 & -17.17 & -27.63 & -13.70 & -20.43 & -27.05 & -18.54 & -15.58 \\
\hline Govt & & -0.557 & -0.332 & & -0.349 & -0.530 & & -1.827 & -1.035 \\
\hline \multirow{3}{*}{ Corp } & & -12.99 & -8.62 & & -6.88 & -8.22 & & -28.61 & -15.98 \\
\hline & & & 0.027 & & & 0.254 & & & -0.082 \\
\hline & & & 0.41 & & & 3.22 & & & -1.35 \\
\hline
\end{tabular}


Table 5. GARCH model for excess returns: Asymmetric impact

This table reports quasi-maximum likelihood (QML) estimates (and their robust $t$ statistics (Bollerslev and Wooldridge, 1992)) for the GARCH(1,1) model of Eq. (4):

$$
\begin{aligned}
r_{t}^{i} & =\mu_{i}+\rho_{i} r_{t-1}^{i}+\gamma_{i}^{e}(0,+) I_{t}^{e}(0,+)+\gamma_{i}^{e}(0,-) I_{t}^{e}(0,-)+\varepsilon_{t}^{i} \\
\varepsilon_{t}^{i} & =\sqrt{s_{t}^{i \pm}} e_{t}^{i} \quad e_{t}^{i} \mid \digamma_{t-1} \sim N\left(0, h_{t}^{i}\right) \\
h_{t}^{i} & =\omega_{i}+\alpha_{i}\left(e_{t-1}^{i}\right)^{2}+\beta_{i} h_{t-1}^{i}
\end{aligned}
$$

where $\digamma_{t-1}$ denotes the information set, $s_{t}^{i \pm}=1+\sum_{k=-1}^{+1} \delta_{i}^{e}(k,+) I_{t}^{e}(k,+)+$ $\sum_{k=-1}^{+1} \delta_{i}^{e}(k,-) I_{t}^{e}(k,-), r_{t}^{i}$ is the daily continuously compounded excess return on asset $i$ (described in Section 4), and $e=f e d, c p i$, une, or pay are the surprise macroeconomic events in our sample such that $I_{t}^{\text {fed }}(k,+)$ is a dummy variable equal to one if the Federal Reserve announced a surprise rate increase on day $t+k$ and zero otherwise, $I_{t}^{f e d}(k,-)$ is a dummy variable equal to one if the Federal Reserve announced a surprise rate decrease or if rates were surprisingly unchanged on day $t+k$ and zero otherwise, $I_{t}^{c p i}(k,+)$ is a dummy variable equal to one if the CPI was reported at day $t+k$ to have surprisingly increased with respect to the previous month and zero otherwise, $I_{t}^{c p i}(k,-)$ is a dummy variable equal to one if the CPI was reported on day $t+k$ to have surprisingly decreased or to have surprisingly remained unchanged with respect to the previous month and zero otherwise, $I_{t}^{u n e}(k,+)$ is a dummy variable equal to one if the unemployment rate was reported on day $t+k$ to have surprisingly increased with respect to the previous month and zero otherwise, $I_{t}^{\text {une }}(k,-)$ is a dummy variable equal to one if the unemployment rate was reported on day $t+k$ to have surprisingly decreased or to have surprisingly remained unchanged with respect to the previous month and zero otherwise, $I_{t}^{\text {pay }}(k,+)$ is a dummy variable equal to one if the nonfarm payroll was reported on day $t+k$ to have surprisingly increased or to have surprisingly remained unchanged with respect to the previous month and zero otherwise, and finally $I_{t}^{p a y}(k,-)$ is a dummy variable equal to one if the nonfarm payroll was reported on day $t+k$ to have surprisingly decreased with respect to the previous month and zero otherwise. Returns are expressed in percentage, i.e., multiplied by 100. Eq. (4) is estimated over a sample from January 3, 1986 to February 14, 2002, i.e., over 4069 observations. A "* ", "** ", or " *** " indicate significance at the $10 \%, 5 \%$, or $1 \%$ level, respectively. 
Table 5 (Continued).

\begin{tabular}{|c|c|c|c|c|c|c|c|}
\hline & \multicolumn{7}{|c|}{ "Daily excess holding-period returns } \\
\hline & $r_{t}^{n y x}$ & $r_{t}^{n a q}$ & $r_{t}^{5 y}$ & $r_{t}^{10 y}$ & $r_{t}^{30 y}$ & $r_{t}^{a a a}$ & $r_{t}^{b a a}$ \\
\hline \multirow{2}{*}{$\gamma_{i}^{f e d}(0,+)$} & -0.237 & -0.393 & -0.008 & -0.049 & -0.135 & -0.123 & -0.157 \\
\hline & -0.83 & -1.55 & -0.16 & -0.57 & -1.06 & -0.98 & -1.28 \\
\hline \multirow[t]{2}{*}{$\gamma_{i}^{f e d}(0,-)$} & $0.334^{* *}$ & $0.408^{* * *}$ & -0.027 & -0.053 & -0.068 & -0.008 & -0.001 \\
\hline & 1.96 & 2.91 & -0.60 & -0.74 & -0.63 & -0.14 & -0.02 \\
\hline \multirow{2}{*}{$\delta_{i}^{f e d}(-1,+)$} & $-0.557^{* * *}$ & $-0.492^{* * *}$ & $1.436^{*}$ & 1.087 & 0.932 & 0.205 & -0.271 \\
\hline & -3.63 & -2.72 & 1.77 & 1.55 & 1.44 & 0.42 & -0.37 \\
\hline \multirow[t]{2}{*}{$\delta_{i}^{f e d}(0,+)$} & 2.193 & 1.023 & $-0.596^{* * *}$ & $-0.581^{* * *}$ & $-0.579^{* * *}$ & -0.276 & 0.474 \\
\hline & 1.37 & 1.12 & -3.15 & -2.95 & -2.90 & -0.62 & 0.36 \\
\hline \multirow[t]{2}{*}{$\delta_{i}^{f e d}(1,+)$} & -0.269 & 0.137 & 0.541 & 0.613 & 0.421 & 0.253 & 0.231 \\
\hline & -0.57 & 0.36 & 1.02 & 1.11 & 0.86 & 0.29 & 0.21 \\
\hline \multirow{2}{*}{$\delta_{i}^{f e d}(-1,-)$} & $-0.363^{* * *}$ & $-0.396^{* * *}$ & $-0.278^{* *}$ & $-0.345^{* * *}$ & $-0.349^{* * *}$ & -0.248 & -0.242 \\
\hline & -2.55 & -3.37 & -1.99 & -2.74 & -2.81 & -1.54 & -1.25 \\
\hline \multirow{2}{*}{$\delta_{i}^{f e d}(0,-)$} & 0.258 & 0.408 & -0.261 & 0.218 & $0.798^{*}$ & -0.060 & -0.089 \\
\hline & 0.40 & 1.18 & -1.35 & 0.69 & 1.70 & -0.21 & -0.32 \\
\hline \multirow[t]{2}{*}{$\delta_{i}^{f e d}(1,-)$} & 0.140 & 0.058 & $1.044^{* * *}$ & 0.245 & -0.183 & 0.394 & 0.554 \\
\hline & 0.49 & 0.29 & 2.64 & 1.02 & -1.18 & 0.96 & 1.40 \\
\hline \multirow[t]{2}{*}{$\gamma_{i}^{c p i}(0,+)$} & $0.151^{* *}$ & 0.173 & -0.032 & -0.045 & -0.082 & $-0.056^{*}$ & $-0.059^{*}$ \\
\hline & 2.27 & 1.51 & -1.06 & -1.20 & -1.16 & -1.84 & -1.90 \\
\hline \multirow[t]{2}{*}{$\gamma_{i}^{c p i}(0,-)$} & $-0.582^{*}$ & -0.487 & -0.053 & -0.079 & -0.157 & -0.019 & 0.002 \\
\hline & -1.83 & -1.17 & -0.58 & -0.64 & -1.23 & -0.22 & 0.03 \\
\hline \multirow[t]{2}{*}{$\delta_{i}^{c p i}(-1,+)$} & 0.179 & 0.237 & 0.207 & 0.139 & 0.016 & -0.167 & -0.144 \\
\hline & 1.33 & 1.25 & 1.22 & 0.92 & 0.13 & -1.59 & -1.32 \\
\hline \multirow[t]{2}{*}{$\delta_{i}^{c p i}(0,+)$} & $0.650^{* *}$ & 0.409 & $-0.342^{*}$ & $-0.283^{* *}$ & -0.183 & -0.155 & $-0.279^{* *}$ \\
\hline & 2.50 & 0.91 & -1.79 & -2.41 & -1.42 & -1.16 & -2.41 \\
\hline \multirow[t]{2}{*}{$\delta_{i}^{c p i}(1,+)$} & $-0.374^{* * *}$ & -0.382 & 0.271 & 0.199 & 0.196 & 0.198 & $0.361^{* *}$ \\
\hline & -4.66 & -3.88 & 1.43 & 1.35 & 1.00 & 1.32 & 2.10 \\
\hline \multirow{2}{*}{$\delta_{i}^{c p i}(-1,-)$} & $-0.649^{* * *}$ & -0.241 & $-0.470^{* *}$ & -0.284 & 0.566 & 0.087 & -0.041 \\
\hline & -7.42 & -1.13 & -2.15 & -1.19 & 1.12 & 0.24 & -0.13 \\
\hline \multirow[t]{2}{*}{$\delta_{i}^{c p i}(0,-)$} & 0.064 & 0.630 & $-0.460^{* *}$ & -0.338 & $-0.781^{* * *}$ & $-0.635^{* * *}$ & $-0.599^{* * *}$ \\
\hline & 0.18 & 1.01 & -2.03 & -1.36 & -13.53 & -4.28 & -3.69 \\
\hline \multirow[t]{2}{*}{$\delta_{i}^{c p i}(1,-)$} & $3.249^{* *}$ & 0.488 & $1.957^{*}$ & $0.991^{*}$ & 1.765 & $0.935^{*}$ & $1.235^{* *}$ \\
\hline & 2.05 & 0.58 & 1.86 & 1.77 & 1.63 & 1.70 & 1.99 \\
\hline
\end{tabular}


Table 5 (Continued).

\begin{tabular}{|c|c|c|c|c|c|c|c|}
\hline & \multicolumn{7}{|c|}{ "Daily excess holding-period returns } \\
\hline & $r_{t}^{n y x}$ & $r_{t}^{n a q}$ & $r_{t}^{5 y}$ & $r_{t}^{10 y}$ & $r_{t}^{30 y}$ & $r_{t}^{a a a}$ & $r_{t}^{b a a}$ \\
\hline \multirow{2}{*}{$\gamma_{i}^{u n e}(0,+)$} & -0.088 & -0.078 & -0.045 & -0.053 & -0.041 & 0.021 & -0.017 \\
\hline & -0.62 & -0.57 & -1.31 & -0.90 & -0.45 & 0.39 & -0.37 \\
\hline \multirow[t]{2}{*}{$\gamma_{i}^{u n e}(0,-)$} & 0.081 & 0.123 & -0.020 & -0.019 & 0.006 & 0.004 & 0.004 \\
\hline & 0.80 & 1.62 & -0.80 & -0.53 & 0.11 & 0.15 & 0.13 \\
\hline \multirow[t]{2}{*}{$\delta_{i}^{u n e}(-1,+)$} & $-0.287^{*}$ & -0.236 & 0.311 & -0.064 & -0.133 & $-0.275^{*}$ & 0.079 \\
\hline & -1.85 & -1.60 & 0.91 & -0.35 & -0.80 & -1.91 & 0.37 \\
\hline \multirow[t]{2}{*}{$\delta_{i}^{u n e}(0,+)$} & $0.998^{*}$ & 0.463 & $-0.791^{* * *}$ & $-0.635^{* * *}$ & $-0.562^{* * *}$ & -0.211 & $-0.439^{* * *}$ \\
\hline & 1.66 & 1.27 & -7.84 & -6.49 & -4.85 & -1.00 & -2.95 \\
\hline \multirow[t]{2}{*}{$\delta_{i}^{u n e}(1,+)$} & -0.091 & 0.108 & $3.000^{* * *}$ & $2.180^{* * *}$ & $1.589^{* * *}$ & $1.099^{* * *}$ & $1.019^{* * *}$ \\
\hline & -0.40 & 0.51 & 3.49 & 3.49 & 3.11 & 2.69 & 2.61 \\
\hline \multirow{2}{*}{$\delta_{i}^{u n e}(-1,-)$} & $-0.215^{*}$ & 0.135 & 0.457 & $0.550^{* *}$ & $0.647^{* * *}$ & $0.403^{* *}$ & $0.352^{*}$ \\
\hline & -1.84 & 0.85 & 1.31 & 2.35 & 2.58 & 1.97 & 1.78 \\
\hline \multirow[t]{2}{*}{$\delta_{i}^{u n e}(0,-)$} & $0.844^{*}$ & 0.138 & $-0.749^{* * *}$ & $-0.724^{* * *}$ & $-0.716^{* * *}$ & $-0.576^{* * *}$ & $-0.600^{* * *}$ \\
\hline & 1.65 & 0.66 & -13.37 & -14.11 & -13.68 & -7.64 & -8.40 \\
\hline \multirow[t]{2}{*}{$\delta_{i}^{u n e}(1,-)$} & $-0.263^{* *}$ & -0.196 & $1.781^{* * *}$ & $1.550^{* * *}$ & $1.289^{* * *}$ & $0.709^{* * *}$ & $0.923^{* * *}$ \\
\hline & -2.04 & -1.63 & 2.80 & 4.52 & 4.27 & 3.12 & 3.58 \\
\hline \multirow[t]{2}{*}{$\gamma_{i}^{p a y}(0,+)$} & 0.034 & 0.046 & $-0.056^{* * *}$ & $-0.063^{*}$ & -0.053 & -0.002 & -0.007 \\
\hline & 0.42 & 0.59 & -2.70 & -1.87 & -0.96 & -0.09 & -0.19 \\
\hline \multirow[t]{2}{*}{$\gamma_{i}^{p a y}(0,-)$} & -0.097 & -0.240 & -0.049 & -0.061 & -0.094 & 0.011 & -0.082 \\
\hline & -0.75 & -1.39 & -1.15 & -0.75 & -0.74 & 0.15 & -1.23 \\
\hline \multirow[t]{2}{*}{$\delta_{i}^{p a y}(-1,+)$} & $-0.248^{* * *}$ & -0.111 & 0.230 & 0.251 & 0.252 & $0.346^{* *}$ & 0.074 \\
\hline & -2.89 & -1.02 & 1.40 & 1.50 & 0.90 & 1.97 & 0.42 \\
\hline \multirow[t]{2}{*}{$\delta_{i}^{p a y}(0,+)$} & $0.900^{* * *}$ & 0.200 & $-0.782^{* * *}$ & $-0.730^{* * *}$ & $-0.676^{* * *}$ & $-0.623^{* * *}$ & $-0.636^{* * *}$ \\
\hline & 3.20 & 1.07 & -20.87 & -16.20 & -8.86 & -10.48 & -9.65 \\
\hline \multirow[t]{2}{*}{$\delta_{i}^{p a y}(1,+)$} & -0.153 & 0.068 & $2.636^{* * *}$ & $1.957^{* * *}$ & $1.387^{* * *}$ & $1.063^{* * *}$ & $1.366^{* * *}$ \\
\hline & -1.30 & 0.47 & 5.91 & 5.47 & 2.02 & 4.35 & 3.03 \\
\hline \multirow[t]{2}{*}{$\delta_{i}^{p a y}(-1,-)$} & 0.053 & 0.404 & 0.108 & $-0.321^{*}$ & -0.293 & $-0.465^{* * *}$ & -0.144 \\
\hline & 0.22 & 1.22 & 0.40 & -1.94 & -1.40 & -3.48 & -0.75 \\
\hline \multirow[t]{2}{*}{$\delta_{i}^{p a y}(0,-)$} & 0.367 & -0.019 & $-0.664^{* * *}$ & $-0.406^{* *}$ & $-0.405^{*}$ & 0.019 & $-0.363^{*}$ \\
\hline & 0.88 & -0.07 & -6.05 & -2.09 & -1.92 & 0.06 & -1.70 \\
\hline \multirow[t]{2}{*}{$\delta_{i}^{p a y}(1,-)$} & -0.156 & 0.113 & $2.344^{* * *}$ & $1.632^{* * *}$ & $1.556^{* *}$ & $1.212^{* *}$ & $1.200^{* *}$ \\
\hline & -0.82 & 0.45 & 2.91 & 2.59 & 2.34 & 2.47 & 2.32 \\
\hline
\end{tabular}




\section{Table 6. DCC IMA model: Asymmetric covariance shifts}

This table reports intra and across-asset class averages of quasi-maximum likelihood (QML) estimates (and of their robust $t$-statistics (Bollerslev and Wooldridge, 1992)) for the DCC IMA model of Eq. (5) from the standardized residuals of the GARCH(1,1) model of Eq. (4):

$$
\eta_{t}^{i} \eta_{t}^{j}=s_{t}^{i \pm *} \eta_{t-1}^{i} \eta_{t-1}^{j}+\left(q_{t}^{i j}-\eta_{t}^{i} \eta_{t}^{j}\right)-\lambda^{e} s_{t}^{i \pm *}\left(q_{t-1}^{i j}-\eta_{t-1}^{i} \eta_{t-1}^{j}\right)
$$

where $s_{t}^{i \pm *}=1+\sum_{k=-1}^{+1} d_{i}^{e}(k,+) I_{t}^{e}(k,+)+\sum_{k=-1}^{+1} d_{i}^{e}(k,-) I_{t}^{e}(k,-), \eta_{t}^{i}=$ $\frac{\varepsilon_{t}^{i}}{\sqrt{s_{t}^{i \pm} h_{t}^{i}}}$ is the daily standardized error from the expression for $r_{t}^{i}$, the excess return on asset $i$, in Eq. (4), and $e=f e d$, cpi, une, or pay are the surprise macroeconomic events in our sample such that $I_{t}^{f e d}(k,+)$ is a dummy variable equal to one if the Federal Reserve announced a surprise rate increase on day $t+k$ and zero otherwise, $I_{t}^{f e d}(k,-)$ is a dummy variable equal to one if the Federal Reserve announced a surprise rate decrease or if rates were surprisingly unchanged on day $t+k$ and zero otherwise, $I_{t}^{c p i}(k,+)$ is a dummy variable equal to one if the CPI was reported at day $t+k$ to have surprisingly increased with respect to the previous month and zero otherwise, $I_{t}^{c p i}(k,-)$ is a dummy variable equal to one if the CPI was reported on day $t+k$ to have surprisingly decreased or to have surprisingly remained unchanged with respect to the previous month and zero otherwise, $I_{t}^{u n e}(k,+)$ is a dummy variable equal to one if the unemployment rate was reported on day $t+k$ to have surprisingly increased with respect to the previous month and zero otherwise, $I_{t}^{\text {une }}(k,-)$ is a dummy variable equal to one if the unemployment rate was reported on day $t+k$ to have surprisingly decreased or to have surprisingly remained unchanged with respect to the previous month and zero otherwise, $I_{t}^{\text {pay }}(k,+)$ is a dummy variable equal to one if the nonfarm payroll was reported on day $t+k$ to have surprisingly increased or to have surprisingly remained unchanged with respect to the previous month and zero otherwise, and finally $I_{t}^{\text {pay }}(k,-)$ is a dummy variable equal to one if the nonfarm payroll was reported on day $t+k$ to have surprisingly decreased with respect to the previous month and zero otherwise. Returns are expressed in percentage, i.e., multiplied by 100. Eq. (5) is estimated over a sample from January 3, 1986 to February 14, 2002, i.e., over 4069 observations. The Stock category is made of $i=n y x$, naq; the Govt category is made of $i=5 y, 10 y, 30 y$; the Corp category is made of $i=a a a, b a a$. Averages are calculated for estimates of the dummy coefficients $d_{i}^{e}(k,+)$ or $d_{i}^{e}(k,-)$ among and across asset classes. 
Table 6 (Continued).

\begin{tabular}{|c|c|c|c|c|c|c|c|c|c|}
\hline & \multicolumn{3}{|c|}{$d_{i}^{f e d}(-1,+)$} & \multicolumn{3}{|c|}{$d_{i}^{f e d}(0,+)$} & \multicolumn{3}{|c|}{$d_{i}^{f e d}(1,+)$} \\
\hline \multirow{3}{*}{ Stock } & Stock & Govt & Corp & Stock & Govt & Corp & Stock & Govt & Corp \\
\hline & -0.942 & -1.118 & -1.002 & -1.670 & -0.980 & -0.991 & -0.742 & -1.090 & -0.916 \\
\hline & -9.64 & -7.59 & -6.61 & -9.83 & -6.98 & -8.04 & -5.57 & -7.38 & -5.33 \\
\hline \multirow[t]{2}{*}{ Govt } & & -0.061 & 0.111 & & -0.903 & -1.054 & & -1.474 & -1.361 \\
\hline & & -0.32 & 0.51 & & -5.80 & -6.51 & & -8.89 & -8.41 \\
\hline \multirow[t]{4}{*}{ Corp } & & & 0.375 & & & -1.766 & & & -0.347 \\
\hline & & & 1.48 & & & -9.69 & & & -2.30 \\
\hline & \multicolumn{3}{|c|}{$d_{i}^{f e d}(-1,-)$} & \multicolumn{3}{|c|}{$d_{i}^{f e d}(0,-)$} & \multicolumn{3}{|c|}{$d_{i}^{f e d}(1,-)$} \\
\hline & Stock & Govt & Corp & Stock & Govt & Corp & Stock & Govt & Corp \\
\hline \multirow[t]{2}{*}{ Stock } & -0.426 & -1.012 & -0.817 & -0.199 & -0.678 & -1.050 & -0.885 & -1.127 & -1.128 \\
\hline & -5.17 & -13.40 & -9.41 & -2.09 & -8.25 & -10.21 & -22.11 & -15.73 & -13.51 \\
\hline Govt & & -0.847 & -0.805 & & -0.709 & -0.361 & & -0.537 & -0.564 \\
\hline \multirow{4}{*}{ Corp } & & -14.28 & -12.54 & & -5.93 & -2.89 & & -9.62 & -7.46 \\
\hline & & & -0.554 & & & -2.131 & & & 0.278 \\
\hline & & & -7.90 & & & -15.84 & & & 2.12 \\
\hline & \multicolumn{3}{|c|}{$d_{i}^{c p i}(-1,+)$} & \multicolumn{3}{|c|}{$d_{i}^{c p i}(0,+)$} & \multicolumn{3}{|c|}{$d_{i}^{c p i}(1,+)$} \\
\hline \multirow{3}{*}{ Stock } & Stock & Govt & Corp & Stock & Govt & Corp & Stock & Govt & Corp \\
\hline & 0.631 & -0.396 & -1.867 & -0.046 & -1.045 & -0.607 & -0.569 & -1.054 & -0.853 \\
\hline & 6.31 & -1.02 & -28.39 & -0.60 & -12.44 & -9.05 & -10.58 & -11.01 & -12.52 \\
\hline Govt & & 2.532 & -1.370 & & -0.448 & -0.481 & & -0.370 & -0.580 \\
\hline \multirow{4}{*}{ Corp } & & 10.68 & -14.98 & & -7.48 & -7.89 & & -5.89 & -8.90 \\
\hline & & & -0.082 & & & -0.282 & & & -0.457 \\
\hline & & & -1.21 & & & -4.43 & & & -7.44 \\
\hline & \multicolumn{3}{|c|}{$d_{i}^{c p i}(-1,-)$} & \multicolumn{3}{|c|}{$d_{i}^{c p i}(0,-)$} & \multicolumn{3}{|c|}{$d_{i}^{c p i}(1,-)$} \\
\hline \multirow{3}{*}{ Stock } & Stock & Govt & Corp & Stock & Govt & Corp & Stock & Govt & Corp \\
\hline & -2.144 & -0.959 & -1.317 & 1.092 & -1.550 & -1.014 & -0.974 & -1.006 & -1.012 \\
\hline & -10.43 & -6.68 & -8.12 & 2.91 & -7.73 & -6.89 & -8.41 & -8.08 & -8.48 \\
\hline Govt & & -0.816 & -0.984 & & -0.641 & -0.870 & & -0.559 & -1.509 \\
\hline \multirow{3}{*}{ Corp } & & -6.16 & -10.12 & & -4.94 & -5.32 & & -3.66 & -6.98 \\
\hline & & & -0.896 & & & -0.784 & & & 0.683 \\
\hline & & & -14.84 & & & -4.91 & & & 2.34 \\
\hline
\end{tabular}


Table 6 (Continued).

\begin{tabular}{|c|c|c|c|c|c|c|c|c|c|}
\hline & \multicolumn{3}{|c|}{$d_{i}^{\text {une }}(-1,+)$} & \multicolumn{3}{|c|}{$d_{i}^{\text {une }}(0,+)$} & \multicolumn{3}{|c|}{$d_{i}^{u n e}(1,+)$} \\
\hline \multirow{3}{*}{ Stock } & Stock & Govt & Corp & Stock & Govt & Corp & Stock & Govt & Corp \\
\hline & -0.381 & -0.885 & -1.029 & -0.237 & -1.126 & -0.962 & -0.601 & -0.913 & -1.006 \\
\hline & -4.73 & -12.92 & -14.53 & -2.59 & -10.14 & -9.52 & -8.60 & -7.38 & -10.14 \\
\hline \multirow[t]{2}{*}{ Govt } & & -0.414 & -0.021 & & 0.029 & -0.729 & & -1.210 & -0.876 \\
\hline & & -6.50 & -5.45 & & 0.11 & -4.83 & & -13.15 & -9.75 \\
\hline \multirow[t]{4}{*}{ Corp } & & & 0.642 & & & 0.431 & & & -0.345 \\
\hline & & & 3.87 & & & 2.96 & & & -4.37 \\
\hline & & ee $(-1$ & & & ine $(0$, & & & ine $(1$, & \\
\hline & Stock & Govt & Corp & Stock & Govt & Corp & Stock & Govt & Corp \\
\hline \multirow[t]{2}{*}{ Stock } & 0.000 & -0.953 & -0.999 & -0.167 & -1.175 & -1.101 & -1.627 & -1.027 & -1.037 \\
\hline & 0.00 & -11.12 & -15.07 & -2.17 & -15.34 & -14.86 & -22.94 & -15.68 & -14.45 \\
\hline \multirow[t]{2}{*}{ Govt } & & -0.769 & -0.815 & & -0.765 & -0.860 & & -0.184 & -0.464 \\
\hline & & -14.16 & -13.40 & & -15.53 & -18.36 & & -2.46 & -5.65 \\
\hline \multirow[t]{4}{*}{ Corp } & & & -0.743 & & & -0.711 & & & -0.080 \\
\hline & & & -14.36 & & & -14.25 & & & -1.01 \\
\hline & & $y(-1$, & & & oay $(0,-$ & & & oay $(1,-$ & \\
\hline & Stock & Govt & Corp & Stock & Govt & Corp & Stock & Govt & Corp \\
\hline \multirow[t]{2}{*}{ Stock } & -0.645 & -1.004 & -1.027 & -0.026 & -1.104 & -0.997 & -1.446 & -0.979 & -0.934 \\
\hline & -14.41 & -15.47 & -17.28 & -0.34 & -14.06 & -12.49 & -25.17 & -17.18 & -14.49 \\
\hline \multirow[t]{2}{*}{ Govt } & & -0.633 & -0.750 & & -0.594 & -0.691 & & -0.721 & -0.369 \\
\hline & & -14.52 & -17.47 & & -12.45 & -14.52 & & -9.70 & -4.91 \\
\hline \multirow[t]{4}{*}{ Corp } & & & -0.470 & & & -0.605 & & & 0.068 \\
\hline & & & -10.23 & & & -13.07 & & & 0.88 \\
\hline & & $(-1$ & & & day $(0$, & & & day $(1$, & \\
\hline & Stock & Govt & Corp & Stock & Govt & Corp & Stock & Govt & Corp \\
\hline \multirow[t]{2}{*}{ Stock } & -0.457 & -0.909 & -1.062 & -0.321 & -1.229 & -0.949 & -0.388 & -1.165 & -1.189 \\
\hline & -5.21 & -12.55 & -14.35 & -3.27 & -11.77 & -8.54 & -3.81 & -10.66 & -11.15 \\
\hline \multirow[t]{2}{*}{ Govt } & & -0.262 & -2.239 & & -0.158 & 0.002 & & -1.201 & -0.768 \\
\hline & & -3.79 & -11.52 & & -1.42 & -0.14 & & -11.42 & -8.61 \\
\hline \multirow[t]{2}{*}{ Corp } & & & 1.148 & & & 0.239 & & & -0.377 \\
\hline & & & 4.41 & & & 1.53 & & & -4.44 \\
\hline
\end{tabular}




\section{Table 7. GARCH model for excess returns: Expected events}

This table reports quasi-maximum likelihood (QML) estimates (and their robust $t$ statistics (Bollerslev and Wooldridge, 1992)) for the $\operatorname{GARCH}(1,1)$ model of Eq. (1):

$$
\begin{aligned}
r_{t}^{i} & =\mu_{i}+\rho_{i} r_{t-1}^{i}+\gamma_{i}(0) I_{t}(0)+\varepsilon_{t}^{i} \\
\varepsilon_{t}^{i} & =\sqrt{s_{t}^{i}} e_{t}^{i} \quad e_{t}^{i} \mid \digamma_{t-1} \sim N\left(0, h_{t}^{i}\right) \\
h_{t}^{i} & =\omega_{i}+\alpha_{i}\left(e_{t-1}^{i}\right)^{2}+\beta_{i} h_{t-1}^{i}
\end{aligned}
$$

where $\digamma_{t-1}$ denotes the information set, $s_{t}^{i}=1+\sum_{k=-1}^{+1} \delta_{i}(k) I_{t}(k), r_{t}^{i}$ is the daily continuously compounded excess return on asset $i$ (see Section 4 ). In Panel A, $I_{t}(k)=1$ if either an expected Federal Reserve rate change $\left(I_{t}^{f e d}(k)=1\right)$, or an expected CPI $\left(I_{t}^{c p i}(k)=1\right)$, unemployment $\left(I_{t}^{u n e}(k)=1\right)$, or payroll announcement $\left(I_{t}^{\text {pay }}(k)=1\right)$ was made on day $t+k$ and zero otherwise; in Panel $\mathrm{B}$, we consider each event $e$ separately $\left(I_{t}(k)=I_{t}^{e}(k)\right)$. Returns are in percentage. Eq. (1) is estimated over a sample from January 3, 1986 to February 14, 2002 (i.e., 4069 observations). Log L is the value of the log likelihood function of Eq. (1) at convergence. A "**, " ** ", or "*** " indicate significance at the $10 \%, 5 \%$, or $1 \%$ level, respectively.

\begin{tabular}{cccccccc}
\hline \hline & \multicolumn{7}{c}{ Panel A: All events } \\
\cline { 2 - 7 } & $r_{t}^{\text {nyx }}$ & $r_{t}^{\text {naq }}$ & $r_{t}^{5 y}$ & $r_{t}^{10 y}$ & $r_{t}^{30 y}$ & $r_{t}^{a a a}$ & $r_{t}^{\text {baa }}$ \\
\hline$\mu_{i}$ & $0.062^{* * *}$ & $0.071^{* * *}$ & $0.029^{* * *}$ & $0.035^{* * *}$ & $0.044^{* * *}$ & $0.040^{* * *}$ & $0.044^{* * *}$ \\
& 5.41 & 5.54 & 7.03 & 5.23 & 4.23 & 7.60 & 8.15 \\
$\rho_{i}$ & $0.109^{* * *}$ & $0.173^{* * *}$ & $0.069^{* * *}$ & $0.072^{* * *}$ & $0.037^{* *}$ & $0.096^{* * *}$ & $0.072^{* * *}$ \\
& 6.35 & 10.16 & 4.10 & 4.30 & 2.26 & 5.79 & 4.36 \\
$\gamma_{i}(0)$ & 0.091 & 0.042 & 0.001 & 0.035 & 0.062 & $0.047^{*}$ & 0.032 \\
& 1.44 & 0.66 & 0.06 & 1.10 & 1.23 & 1.89 & 1.37 \\
\hline$\omega_{i}$ & $0.019^{* * *}$ & $0.023^{* * *}$ & $0.003^{* * *}$ & $0.006^{* * *}$ & $0.008^{* * *}$ & $0.001^{* * *}$ & $0.001^{* * *}$ \\
& 4.84 & 6.45 & 4.29 & 4.19 & 3.77 & 2.91 & 3.32 \\
$\alpha_{i}$ & $0.107^{* * *}$ & $0.156^{* * *}$ & $0.061^{* * *}$ & $0.052^{* * *}$ & $0.033^{* * *}$ & $0.060^{* * *}$ & $0.057^{* * *}$ \\
& 9.38 & 11.19 & 7.10 & 6.91 & 6.65 & 8.01 & 7.78 \\
$\beta_{i}$ & $0.875^{* * *}$ & $0.837^{* * *}$ & $0.903^{* * *}$ & $0.920^{* * *}$ & $0.948^{* * *}$ & $0.939^{* * *}$ & $0.941^{* * *}$ \\
& 65.65 & 64.59 & 59.55 & 76.28 & 120.74 & 126.79 & 124.25 \\
$\delta_{i}(-1)$ & -0.100 & -0.035 & 0.018 & 0.058 & 0.133 & 0.102 & $0.249^{*}$ \\
$\delta_{i}(0)$ & -1.04 & -0.33 & 0.15 & 0.51 & 1.16 & 0.90 & 1.92 \\
$\delta_{i}(1)$ & 0.169 & -0.019 & $-0.260^{* *}$ & $-0.288^{* * *}$ & $-0.269^{* * *}$ & $-0.246^{* *}$ & $-0.272^{* * *}$ \\
\hline \hline $\log \mathrm{L}$ & -4886.51 & -5805.24 & -447.53 & -2381.91 & -4110.78 & -1790.91 & -1671.64 \\
\hline
\end{tabular}


Table 7 (Continued).

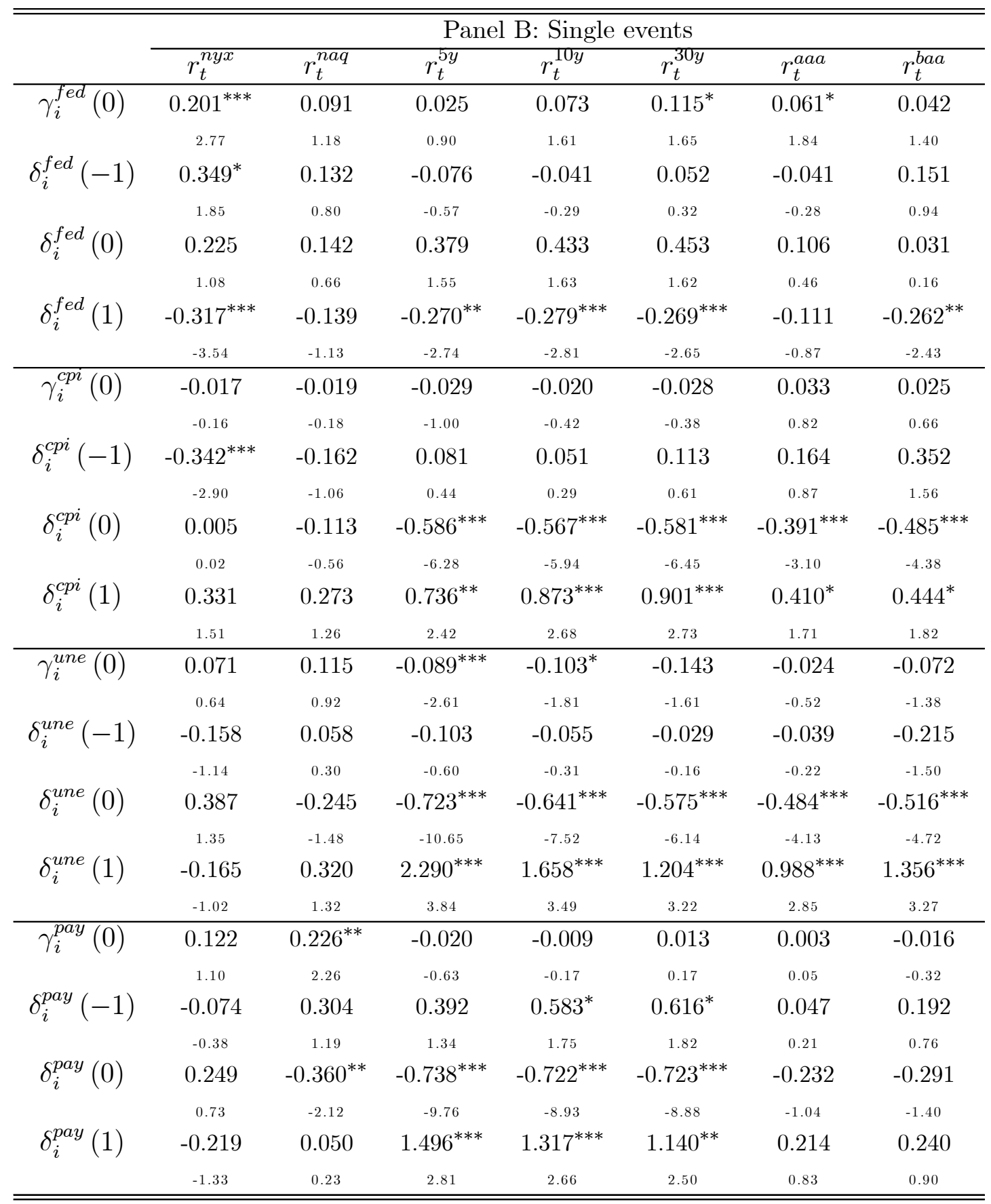


Table 8. DCC IMA model: Expected events

This table reports intra and across-asset class averages of quasi-maximum likelihood (QML) estimates (and of their robust $t$-statistics (Bollerslev and Wooldridge, 1992)) for the DCC IMA model of Eq. (3) from the standardized residuals of the $\operatorname{GARCH}(1,1)$ model of Eq. (1):

$$
\eta_{t}^{i} \eta_{t}^{j}-\eta_{t-1}^{i} \eta_{t-1}^{j}=s_{t}^{i *} \eta_{t-1}^{i} \eta_{t-1}^{j}+\left(q_{t}^{i j}-\eta_{t}^{i} \eta_{t}^{j}\right)-\lambda s_{t}^{i *}\left(q_{t-1}^{i j}-\eta_{t-1}^{i} \eta_{t-1}^{j}\right)
$$

where $s_{t}^{i *}=1+\sum_{k=-1}^{+1} d_{i}(k) I_{t}(k)$ and $\eta_{t}^{i}=\frac{\varepsilon_{t}^{i}}{\sqrt{s_{t}^{i} h_{t}^{i}}}$ is the daily standardized error from the expression for $r_{t}^{i}$, the excess return on asset $i$, in Eq. (1). In Panel A, $I_{t}(k)$ is a dummy variable equal to one if either an expected Federal Reserve rate change took place, or an expected CPI, unemployment, or payroll announcement was made on day $t+k$ and zero otherwise. In Panel B, Eq. (3) is estimated separately for each expected event, i.e., replacing $I_{t}(k)$ with $I_{t}^{e}(k)=1$ if an expected Federal Reserve $(e=f e d)$, CPI $(e=c p i)$, unemployment $(e=u n e)$, or payroll $(e=p a y)$ event took place on day $t+k$ and zero otherwise. Returns are expressed in percentage, i.e., multiplied by 100 . Eq. (3) is estimated over a sample from January 3, 1986 to February 14, 2002, i.e., over 4069 observations. The Stock category is made of $i=n y x$, naq; the Govt category is made of $i=5 y, 10 y, 30 y$; the Corp category is made of $i=a a a$, baa. Averages are calculated for estimates of the dummy coefficients $d_{i}(k)$ among and across asset classes.

\begin{tabular}{|c|c|c|c|c|c|c|c|c|c|}
\hline & \multicolumn{9}{|c|}{ Panel A: All events } \\
\hline & \multicolumn{3}{|c|}{$d_{i}(-1)$} & \multicolumn{3}{|c|}{$d_{i}(0)$} & \multicolumn{3}{|c|}{$d_{i}(1)$} \\
\hline & Stock & Govt & Corp & Stock & Govt & Corp & Stock & Govt & Corp \\
\hline \multirow[t]{2}{*}{ Stock } & -0.794 & -0.904 & -0.890 & -0.424 & -1.026 & -0.892 & -0.146 & -1.016 & -0.952 \\
\hline & -18.32 & -15.04 & -16.19 & -9.03 & -18.55 & -12.24 & -2.64 & -21.80 & -20.42 \\
\hline Govt & & -0.198 & -1.461 & & -0.493 & -0.613 & & -0.358 & -0.498 \\
\hline \multirow{3}{*}{ Corp } & & -3.71 & -26.54 & & -11.65 & -14.51 & & -7.69 & -11.32 \\
\hline & & & -1.774 & & & -0.440 & & & -0.343 \\
\hline & & & -29.19 & & & -10.10 & & & -7.20 \\
\hline
\end{tabular}


Table 8 (Continued).

\begin{tabular}{|c|c|c|c|c|c|c|c|c|c|}
\hline & \multicolumn{9}{|c|}{ "Panel B: Single events } \\
\hline & \multicolumn{3}{|c|}{$d_{i}^{f e d}(-1)$} & \multicolumn{3}{|c|}{$d_{i}^{f e d}(0)$} & \multicolumn{3}{|c|}{$d_{i}^{f e d}(1)$} \\
\hline \multirow{3}{*}{ Stock } & Stock & Govt & Corp & Stock & Govt & Corp & Stock & Govt & Corp \\
\hline & -0.908 & -0.987 & -0.880 & -0.741 & -0.975 & -0.986 & -1.746 & -1.126 & -0.942 \\
\hline & -16.17 & -14.23 & -12.79 & -10.62 & -16.80 & -14.56 & -20.37 & -13.29 & -12.00 \\
\hline \multirow[t]{2}{*}{ Govt } & & -0.563 & -0.806 & & -0.734 & -0.811 & & -0.310 & -0.648 \\
\hline & & -9.58 & -11.13 & & -12.27 & -13.09 & & -4.32 & -7.82 \\
\hline \multirow[t]{4}{*}{ Corp } & & & -0.543 & & & -0.726 & & & -0.016 \\
\hline & & & -9.13 & & & -11.17 & & & -0.19 \\
\hline & & $l_{i}^{c p i}(-1$ & & & $d_{i}^{c p i}(0)$ & & & $d_{i}^{c p i}(1)$ & \\
\hline & Stock & Govt & Corp & Stock & Govt & Corp & Stock & Govt & Corp \\
\hline \multirow[t]{2}{*}{ Stock } & -0.422 & -0.757 & -0.968 & -0.175 & -1.017 & -0.652 & -0.049 & -0.995 & -0.937 \\
\hline & -6.80 & -14.76 & -19.00 & -2.14 & -19.82 & -12.44 & -0.54 & -19.27 & -15.50 \\
\hline \multirow[t]{2}{*}{ Govt } & & -0.621 & -1.375 & & -0.475 & -0.542 & & -0.403 & -0.440 \\
\hline & & -4.94 & -13.06 & & -8.28 & -9.98 & & -6.59 & -7.52 \\
\hline \multirow[t]{4}{*}{ Corp } & & & -0.081 & & & -0.519 & & & -0.437 \\
\hline & & & -0.94 & & & -10.27 & & & -7.57 \\
\hline & & ${ }_{i}{ }_{i n e}(-1$ & & & $d_{i}^{u n e}(0)$ & & & $d_{i}^{u n e}(1)$ & \\
\hline & Stock & Govt & Corp & Stock & Govt & Corp & Stock & Govt & Corp \\
\hline \multirow[t]{2}{*}{ Stock } & -0.402 & -1.187 & -0.926 & -0.156 & -1.174 & -1.170 & -0.687 & -0.930 & -0.936 \\
\hline & -5.09 & -11.67 & -10.64 & -1.57 & -12.72 & -13.02 & -8.57 & -10.24 & -10.03 \\
\hline \multirow[t]{2}{*}{ Govt } & & -0.507 & -0.516 & & -0.641 & -0.656 & & -1.390 & -2.047 \\
\hline & & -7.25 & -7.47 & & -9.08 & -8.87 & & -11.51 & -16.75 \\
\hline \multirow[t]{4}{*}{ Corp } & & & -0.213 & & & -1.598 & & & 0.053 \\
\hline & & & -2.69 & & & -16.54 & & & 0.46 \\
\hline & & $\begin{array}{l}i_{i} a y \\
i\end{array}$ & & & $d_{i}^{p a y}(0)$ & & & $d_{i}^{p a y}(1)$ & \\
\hline & Stock & Govt & Corp & Stock & Govt & Corp & Stock & Govt & Corp \\
\hline \multirow[t]{2}{*}{ Stock } & 0.784 & -1.190 & -0.939 & -0.624 & -1.177 & -1.302 & -0.703 & -0.868 & -0.938 \\
\hline & 3.92 & -10.56 & -8.76 & -7.89 & -12.40 & -13.97 & -8.97 & -5.73 & -8.02 \\
\hline \multirow[t]{2}{*}{ Govt } & & -0.796 & -0.809 & & -0.534 & -0.766 & & -1.221 & -0.724 \\
\hline & & -9.91 & -9.96 & & -6.33 & -7.93 & & -10.87 & -8.14 \\
\hline \multirow[t]{2}{*}{ Corp } & & & -0.564 & & & -1.623 & & & -0.614 \\
\hline & & & -8.01 & & & -13.85 & & & -7.60 \\
\hline
\end{tabular}

